\title{
Interaction of phenothiazines, stilbenes and flavonoids with multidrug resistance-associated transporters, P-glycoprotein and MRP1
}

\author{
Olga Wesołowska ${ }^{\bowtie}$ \\ Department of Biophysics, Wrocław Medical University, Wrocław, Poland
}

Multidrug resistance (MDR) of cancer cells poses a serious obstacle to successful chemotherapy. The overexpression of multispecific ATP-binding cassette transporters appears to be the main mechanism of MDR. A search for MDR-reversing agents able to sensitize resistant cells to chemotherapy is ongoing in the hope of their possible clinical use. Studies of MDR modulators, although they have not produced clinically beneficial effects yet, may greatly enrich our knowledge about MDR transporters, their specificity and mechanism of action, especially substrate and/or inhibitor recognition. In the present review, interactions of three groups of modulators: phenothiazines, flavonoids and stilbenes with both P-glycoprotein and MRP1 are discussed. Each group of compounds is likely to interact with the MDR transporters by a different mechanism. Phenothiazines probably interact with drug binding sites, but they also could indirectly affect the transporter's activity by perturbing lipid bilayers. Flavonoids mainly interact with $A B C$ proteins within their nucleotide-binding domains, though the more hydrophobic flavonoids may bind to regions within transmembrane domains. The possible mechanism of MDR reversal by stilbenes may result from their direct interaction with the transporter (possibly within substrate recognition sites) but some indirect effects such as stilbene-induced changes in gene expression pattern and in apoptotic pathways should also be considered. Literature data as well as some of our recent results are discussed. Special emphasis is put on cases when the interactions of a given compound with both P-glycoprotein and MRP1 have been studied simultaneously.

Keywords: multidrug resistance reversal, phenothiazines, stilbenes, flavonoids, P-glycoprotein (ABCB1), multidrug resistance-associated protein 1 (MRP1, ABCC1)

Received: 04 March, 2011; revised: 09 November, 2011; accepted: 13 December, 2011; available on-line: 20 December, 2011

\section{MULTIDRUG RESISTANCE}

Systemic chemotherapy is currently the main therapeutic method to treat metastasized tumors. Unfortunately, the outcome of the therapy is often fatal mainly due to tumor resistance that may be either an intrinsic feature of the specific cancer type or may be acquired during the course of initial chemotherapy. If cancer cells gain simultaneous resistance to many structurally and functionally unrelated drugs, even those to which they have not been exposed previously, the phenomenon is termed multidrug resistance (MDR) (Kaye, 1988). Resistance to chem- otherapy may include several non-related mechanisms such as: altered transmembrane drug transport (i.e., decreased influx and/or increased efflux); altered drug metabolism; alterations of drug's target; enhanced DNA repair; changes in apoptotic pathways (e.g., resistance to pro-apoptotic signals), and others (Skovsgaard et al., 1994; Lage, 2008). Nevertheless, changes in cellular drug accumulation caused by overexpression of multispecific ATP-binding cassette transporters (ABC transporters) are widely regarded as the main molecular mechanism of MDR (Kane, 1996; Gottesman et al., 1996). To date, 48 $\mathrm{ABC}$ transporters have been identified in humans (Dean, 2005) and twelve of them have been recognized as putative drug transporters (Lage, 2003). However, the vast majority of clinically important cases of MDR seem to be the result of overexpression of only three proteins: P-glycoprotein (P-gp, ABCB1), multidrug resistance-associated protein 1 (MRP1, ABCC1), and breast cancer resistance protein (BCRP, ABCG2) (Sharom, 2008). These transporters use energy of ATP hydrolysis to pump anticancer drugs out of the cell in this way reducing their intracellular concentration and enabling cancer cells to survive (Choudhuri \& Klaassen, 2006). Some aspects of the interaction of substrates and modulators with $\mathrm{P}$ glycoprotein and MRP1 will be shortly described in the present review, but for a full account of the structure and function of $\mathrm{ABC}$ proteins the reader is referred to the recent extensive reviews (Ambudkar et al., 2006; Deeley \& Cole, 2006; Gutmann et al., 2010).

\section{P-GLYCOPROTEIN}

P-glycoprotein is a $170-\mathrm{kDa}$ transmembrane protein that was discovered in 1976 (Juliano \& Ling, 1976). P-gp is physiologically expressed in apical membranes of polarized epithelial cell layers in many secretory, excretory and barrier tissues (Schinkel, 1997). It is believed to play an important role in cellular detoxification by influencing the absorption and tissue penetration of xenobiotics (Fromm, 2000). P-gp transports an enormous number of substrates including anticancer drugs (e.g., anthracyclines, Vinca alkaloids), antifungals, antibiotics, detergents, HIV

e-mail olawes@biofiz.am.wroc.pl

Abbreviations: CPZ, chlorpromazine; FAR, fluorescence activity ratio, defined as intracellular fluorescence intensity of modulatortreated cell population divided by fluorescence intensity of untreated sample; GSH, glutathione; MDR, multidrug resistance; MDR ratio, a ratio of $\mathrm{IC}_{50}$ value of anticancer drug to $\mathrm{IC}_{50}$ of this drug with modulator; MRP1, multidrug resistance-associated protein 1 (ABCC1); NBD, nucleotide-binding domain; P-gp, P-glycoprotein (ABCB1); SAR, structure-activity relationship; TDZ, thioridazine; TFP, trifluoperazine; TMD, transmembrane domain. 
protease inhibitors, and many others (Ambudkar et al., 1999). These compounds share no structural similarity, however, all P-gp substrates are relatively hydrophobic and have a neutral or cationic character under physiological conditions (Gottesman \& Pastan, 1993). Analysis of one hundred compounds whose interaction with P-gp had been previously tested led Seelig (1998) to propose that P-gp required the presence of electron donor groups separated by a fixed distance in the substrate molecules. Two types of substrate recognition elements were defined: type I units (two electron donor groups separated from one another by $2.5 \pm 0.3 \AA$ ) and type II units (two or three electron donor groups separated by 4.6 $\pm 0.6 \AA$ ). These electron donor groups could be e.g., carbonyl, hydroxy, or tertiary amino groups, $\pi$-electron systems, or certain halides. The binding of the substrate to P-gp increased with the number of type I and type II units present in the substrate molecule (Seelig, 1998). In case of molecules possessing an identical number of electron donor units, P-gp binding was proportional to their overall hydrophobicity (Seelig, 1998). Additionally, it was shown that P-gp accepted neutral or cationic type I recognition units, while negatively charged type I units were not accepted in the substrate molecules (Seelig et al., 2000).

\section{Structure}

P-glycoprotein is composed of two transmembrane domains (TMDs) each containing six $\alpha$-helices and two cytoplasmic nucleotide binding domains (NBDs) (Fig. 1A). Early studies that employed mutational analysis and photoaffinity labeling followed by protein digestion identified the substrate binding site to be located within transmembrane domains (reviewed in: Crowley \& Callaghan, 2010). The results pointed to transmembrane helices $3,5,6,8,11$ and 12 to be engaged in formation of the binding site. Additionally, it has been observed that

A

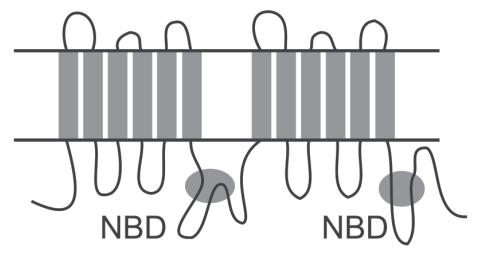

B

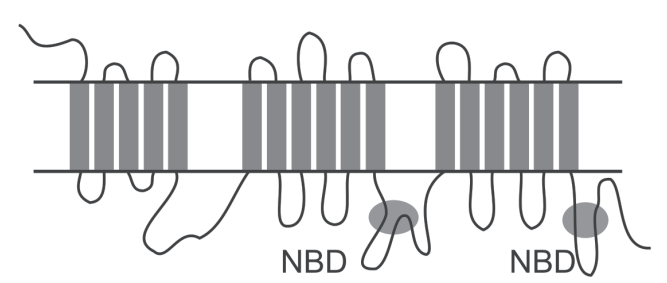

more than one substrate molecule can bind to P-gp at the same time and that different substrates can allosterically modulate each other's transport (Shapiro \& Ling, 1997; Loo et al., 2003). For example, rhodamine 123 was found to bind to a different site on P-gp (R-site) than Hoechst 33342 (H-site) and the two reciprocally stimulated each other's transport (Shapiro \& Ling, 1997). Such observations led many authors to propose that there were several (two to four), partially overlapping, binding sites for different drugs (Dey et al., 1997; Shapiro \& Ling, 1997; Martin et al., 2000; Loo et al., 2003; Lugo \& Sharom, 2005). Nowadays, new structural data on P-gp allow for the integration of these multiple binding sites into one large binding cavity model in which different substrates occupy different regions of the binding pocket and interact with different amino acid residues (Ambudkar et al., 2006; Crowley \& Callaghan, 2010). It seems likely that the existence of such a large, flexible hydrophobic pocket is a common feature of many polyspecific proteins, for example bacterial multidrug-binding transcription factors or multidrug transporters from such superfamilies as the ABC family (ATP-binding cassette), the MSF family (major facilitator superfamily), the RND family (resistance-nodulation-division), and the SMR family (small multidrug resistance) (Higgins, 2007).

Initially, basing on a comparison of structures of many P-gp substrates, aromatic amino acid residues have been proposed to play an important role in the substrate recognition and binding by P-gp (Seelig et al., 2000). This hypothesis was partially corroborated by structural information gained by Aller et al. (2009). The crystal structure of nucleotide-free murine P-gp, obtained at $3.8 \AA$ resolution, revealed an inward-facing structure, with two NBD domains separated from each other by about $30 \AA$ (Fig. 1C). A large internal cavity (about $6000 \AA^{3}$ volume) constituted a putative substrate binding region. This cavity was formed by transmembrane helices and was acces-

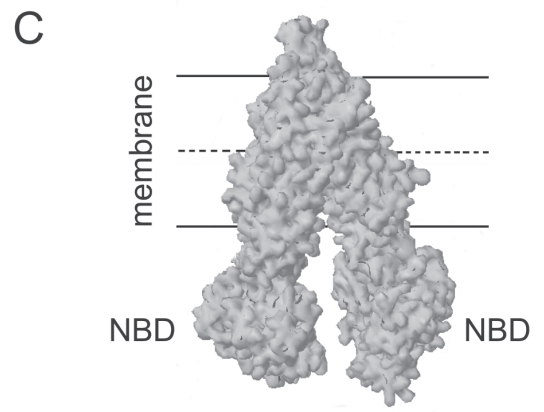

D

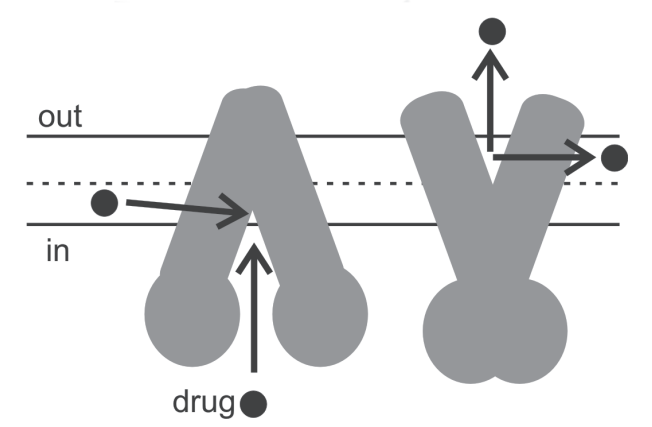

Figure 1. Structure of MDR transporters.

Predicted membrane topology of P-glycoprotein (A) and MRP1 (B), three dimensional structure of P-gp in the inward-facing conformation (C), and model for drug efflux by P-glycoprotein (D) showing its inward-facing structure able to accommodate ligands from the cytoplasm and inner membrane leaflet (left) and its putative outward-facing structure able to release ligands (right). The structure in (C) was generated using StarBiochem application on the basis of mouse P-gp structure of Aller et al. (2009) (PDB accession code 3G5U). 
sible both from the cytoplasm and the inner leaflet of the lipid bilayer. This is in accordance with the molecular "vacuum cleaner" hypothesis that assumes that P-gp can recognize and bind its substrates within the membrane (Raviv et al., 1990). Additionally, a lower resolution structure of P-gp with an inhibitor bound within the cavity was obtained (Aller et al., 2009) and indeed many aromatic amino acid residues were observed to be in close proximity to the inhibitor molecule.

\section{Mechanism of action}

The molecular mechanism of drug transport by P-gp as well as the mechanism of coupling of ATP hydrolysis to drug transport are not fully understood at present. The transporter is characterized by some level of basal ATPase activity that is greatly stimulated in the presence of substrates (Ambudkar et al., 1999). ATPase activity of both NBDs is required for proper P-gp function and the nucleotide is alternately hydrolyzed in both catalytic sites (Senior et al., 1995). It has also been demonstrated that the transport of one drug molecule is accompanied by hydrolysis of two ATP molecules (Sauna \& Ambudkar, 2000).

Biochemical data together with structural data obtained for P-gp and two bacterial ABC transporters (Sav1866 and $\mathrm{MsbA}$ ) allowed a model of conformational changes during P-gp transport cycle to be proposed (Fig. 1D) (Aller et al., 2009; Gutmann et al., 2010). First, a substrate molecule is bound to P-gp that is in a nucleotidefree, inward-facing conformation. Next, binding and/or hydrolysis of ATP induces a conformational change in both NBDs, which approach each other, and in transmembrane domains. This results in an outward-facing conformation with the binding cavity now accessible to the outer leaflet of the cell membrane and the extracellular environment. In this conformation the substrate affinity to P-gp is substantially reduced. The following step is the release of the substrate, and finally P-gp is reset to the inward-facing conformation. This model is in accordance with the one previously proposed by Ambudkar et al. (1999) on the basis of biochemical studies alone. Their model assumed that during the transport cycle the drug-binding site of P-gp altered its conformation between the ON state (high affinity for substrate) and the OFF state (low affinity). Additionally, the model of Gutmann et al. (2010) provides structural basis for the change of P-gp affinity for the substrate during the transport cycle. These authors postulate rotation of P-gp transmembrane helices during the conformational change from the inward- to the outward-facing state. In this way, the amino acid residues that are important for the interaction with the drug in the high-affinity state are facing away from it in the low-affinity state and cannot participate in the drug binding.

\section{MRP1}

Multidrug resistance-associated protein 1 was first identified in 1992 in doxorubicin-resistant lung cancer cells (Cole et al., 1992). Physiologically, MRP1 is expressed mainly in the basolateral membrane of polarized cell layers and its function in non-malignant cells is likely to be the participation in the final steps of cellular detoxification (Keppler et al., 1997). The protein also functions as a glutathione-S-conjugate export pump of erythrocytes (Pulaski et al., 1996) and as a transporter of glutathione-conjugated leukotriene $\mathrm{LTC}_{4}$ in mast cells (Leier et al., 1994), which suggests some role in the modulation of the immune response.

The substrate specificities of MRP1 and P-gP partially overlap; MRP1 confers resistance to many anticancer drugs (e.g., anthracyclines, Vinca alkaloids, etoposide, paclitaxel), antivirals, antibiotics, and other compounds (Leslie et al., 2005; Deeley \& Cole, 2006). In contrast to P-gp, which is an active transporter of unconjugated xenobiotics, MRP1 requires the presence of reduced glutathione (GSH) to transport unmodified anticancer drugs, e.g., vincristine (Loe et al., 1996; Leslie et al., 2005). Substrates predominantly transported by MRP1 are glutathione, glucuronate and sulfate conjugates of organic anions of exogenous and endogenous origin, as well as oxidized glutathione (Keppler et al., 1997). The preference of MRP1 for negatively charged substrates has been corroborated by Seelig et al. (2000) who demonstrated that MRP1, similarly to P-gp, recognized type I and type II electron donor units. MRP1, however, does not transport compounds that contain cationic type I recognition units (such compounds are typical $\mathrm{P}$-gp substrates) and compounds that carry exclusively electrically neutral recognition units are transported only weakly. Good MRP1 substrates contain up to four negatively charged type I recognition units such as the carboxylic acid group, the sulfonic acid group or the sulfate group (Seelig et al., 2000).

\section{Structure}

Structurally, MRP1 and P-gp bear many similarities even though the proteins share only $15 \%$ sequence identity (Cole et al., 1992). MRP1 is a protein of about 190 $\mathrm{kDa}$ and contains two NBDs coupled to two TMDs whose helices form drug binding pocket (reviewed in: Hipfner et al., 1999). An additional N-terminal domain, probably composed of five transmembrane $\alpha$-helices, is present in MRP1 (Fig. 1B). This domain, however, seems to have no importance for substrate binding as N-terminally truncated MRP1 retains its transport function (reviewed in: Deeley \& Cole, 2006). It plays, however, an important role in processing and trafficking of the transporter.

The most recent structure of MRP1 obtained by cryoelectron microscopy of $2 \mathrm{D}$ crystals (Rosenberg et al., 2010) has revealed an inward-facing structure with separated NBD domains similar to the structure obtained previously for P-gp (Aller et al., 2009). Unfortunately, the resolution of the MRP1 structure $\left(1 / 6\right.$ per $\left.\AA^{-1}\right)$ was too low to allow for identification of protein fragments engaged in the formation of the drug binding pocket. Only the spatial orientation of the transmembrane domains was determined as well as the positions of long transmembrane $\alpha$-helices (Rosenberg et al., 2010).

Amino acid residues from both transmembrane domains of MRP1 seem to contribute to its drug binding pocket (reviewed in: Deeley \& Cole, 2006). Mutational, cross-linking and photoaffinity labeling studies have pointed out to the engagement of transmembrane helices 10,11, 16 and 17. Additionally, the linker between the additional N-terminal domain of MRP1 and the first TMD was reported to be essential for substrate recognition (Deeley \& Cole, 2006). Similarly to P-gp, the phenomenon of reciprocal stimulation of transport of one compound by another was also observed for MRP1 and other proteins from the MRP family; in this case one of the substrates was usually GSH (Loe et al., 2000a; Leslie et al., 2003). This was initially interpreted as a co- 
transport of a drug and glutathione by MRP1 (Loe et al., 1998). Further interpretation assumed the existence of two positively cooperative binding sites for a drug (Dsite) and GSH (G-site) (Evers et al., 2000). More recent data seem to corroborate the latter model (for a review see (Borst et al., 2006)). Whether the binding of the drug and glutathione occurs in two separate binding sites or the two putative sites are formed by different regions of one large binding pocket remains to be established. However, by analogy with P-glycoprotein, for which recent data suggest rather the existence of one large hydrophobic pocket, also the presence of one large pocket seems to be more likely for MRP1. It is easy to imagine that binding of one molecule (e.g., GSH) to one region of the relatively flexible binding pocket would change its shape in such a way that the binding of the second substrate would be facilitated.

At present, not much is known about the amino acid residues forming the drug recognition pocket of MRP1. On the basis of molecular modeling Seelig et al. (2000) proposed that the MRP1 binding pocket contained several cationic residues that could form hydrogen bonds with the transported substrates and neutralize their negative charge. However, also aromatic amino acid residues have been proposed to play an important role in drug binding (Campbell et al., 2004). Recent mutational studies have confirmed this notion (reviewed in (Deeley \& Cole, 2006) and several aromatic residues were proposed to form an aromatic "basket" located close to the cytosolic interface of the putative drug binding pocket. However, only a high resolution crystal structure of MRP1 could elucidate the molecular details of substrate recognition by this protein.

\section{Mechanism of action}

MRP1 is characterized by basal ATPase activity comparable to the basal activity of P-gp that can also be stimulated by substrates (Mao et al., 1999). In contrast to P-gp, whose NBD domains are thought to be functionally equivalent, the NBD domains of MRP1 differ in their properties and probably also function (Payen et al., 2003; Yang et al., 2003). The N-terminal NBD (NBD1) binds ATP with high affinity but has low hydrolytic activity, while the opposite is true for the C-terminal NBD (NBD2) (Payen et al., 2003). It has been shown that ATP hydrolysis at NBD2 is crucial for substrate transport by MRP1, while NBD1 is speculated to play a regulatory role (Yang et al., 2005).

The general mechanism of drug transport by MRP1 is believed to be similar to the one of P-glycoprotein. At present there is no data on conformational changes that MRP1 undergoes during the substrate transport cycle.

\section{MULTIDRUG RESISTANCE MODULATORS}

The initial idea to reduce clinical consequences of multidrug resistance was to circumvent this phenomenon by the simultaneous application of anticancer drugs together with inhibitors of MDR transporters, in this way hoping to improve the efficacy of chemotherapy (Beck, 1984; Fojo et al., 1987). Any chemical compound able to interfere with active transport of the drugs out of the cell is termed MDR modulator, reverser or chemosensitizer. An ideal MDR modulator should inhibit drug efflux, increase intracellular accumulation of anticancer agents and, finally, make resistant cells sensitive to the drug again. Of course, such an MDR-reversing agent should be non-toxic itself and should not interfere with other cellular processes. Several putative molecular mechanisms of inhibition of MDR transporters have been proposed by Ambudkar et al. (1999). The authors hypothesized that the modulators could: i) bind directly to the drug binding pocket of an $\mathrm{ABC}$ protein and inhibit substrate transport in a competitive or non-competitive manner; ii) block the binding of ATP to the protein; iii) inhibit ATP hydrolysis; or iv) uncouple ATP hydrolysis from the translocation of the drug. The modulators could also induce changes of the biophysical properties of the lipid bilayer in which the MDR transporter is embedded interfering in this way with its transport activity (Hendrich \& Michalak, 2003).

Since no MDR modulators applicable to regular clinical use have been identified so far, the search is still on. Hundreds of compounds able to inhibit P-glycoprotein or MRP1 have been identified. Their structural diversity is almost as wide as the diversity of substrates recognized by MDR transporters. In order to rationalize the search and synthesis of promising MDR reversal agents many attempts have been made to recognize the features important for their inhibitory activity (for review see Stouch \& Gudmundsson, 2002; McDevitt \& Callaghan, 2007). Early structure-activity relationships (SAR) studies analyzing P-gp inhibitors pointed to their lipophilicity, planar structure, and cationic charge (often located in a cyclic structure containing a nitrogen atom) (Zamora et al., 1988). In their SAR study on about 100 P-gp substrates and modulators Wang et al. (2003) identified the following features characterizing good P-gp inhibitors: i) lipophilicity $(\log \mathrm{P}>2.92)$; ii) long axis of the molecule of minimum 18 carbon atoms; iii) nucleophility; and iv) at least one tertiary amine that could form a cation at physiological $\mathrm{pH}$. Recently, Brocatelli et al. (2011) stressed that P-gp inhibitors should possess a minimum one hydrogen bond acceptor (while hydrogen bond donors are not necessary), an optimal shape of the molecule, as well as at least one large hydrophobic region. When properties that differentiate P-gp substrates from inhibitors are considered, a higher transmembrane diffusion rate of inhibitors than of substrates is frequently mentioned (Eytan et al., 1996; Marbeuf-Gueye et al., 1999).

Structure-activity relationships of MRP1 inhibitors have been less intensively investigated. The majority of reports concentrated on SAR studies of sets of MRP1 inhibitors comprising one group of closely related compounds, e.g., verapamil analogs (Loe et al., 2000b), pyrrolopyrimidines (Tawari et al., 2008), and flavonoids (van Zanden et al., 2004; 2005). Pajeva et al. (2009) used a large set of compounds from three different chemical groups to model the pharmacophores of both P-gp and MRP1. They identified the following features common to the inhibitors of both MDR transporters: i) the presence of at least one hydrogen bond acceptor group (A) of limited flexibility (e.g., in a planar ring system or directly substituted to such a ring); ii) an additional hydrophobic center located far from the group A, preferably in a flexible side chain; iii) a tertiary protonable nitrogen that could be either a hydrogen bond acceptor or donor. Differences between the requirements of the two transporters were also noticed. Namely, MRP1 preferred lower flexibility of group A as compared to P-gp; P-gp required the presence of an additional acceptor group in the molecule; and finally, the distances between the pharmacophore features of similar functionalities dif- 
fered between P-gp and MRP1 (variable in P-gp versus about $5 \AA$ in MRP1) (Pajeva et al., 2009).

Several generations of identified MDR modulators have been clinically tested so far (reviewed in: Lee, 2010; Crowley et al., 2010). The first generation of MDR modulators included compounds known for biological activity of a different type that were additionally observed to inhibit P-glycoprotein (e.g., calcium channel blocker verapamil, antipsychotic trifluoperazine or immunosuppressant cyclosporine A). These compounds failed in clinical studies mostly because of their intrinsic toxicity that resulted in intolerable side effects that prevented obtaining serum levels of the modulators sufficient for effective P-gp inhibition (Raderer \& Scheithauer, 1993). The synthesis of the first generation modulators' derivatives with improved efficacy and reduced toxicity yielded the second generation of putative chemosensitizers (e.g., PCS833 — Valspodar). Their therapeutic use was prevented mainly by their impairment of anticancer drug elimination and metabolism which resulted in greatly increased concentrations of the cytotoxic drugs in patients' plasma (Leonard et al., 2002). This was mainly due to their inhibitory action against not only P-glycoprotein but also cytochrome P450. The third generation of MDR modulators, lacking the disadvantages of their antecedents, that is currently under investigation (e.g., LY335979 - Zosuquidar) gives some hope for effective pharmacological modulation of multidrug resistance. Zosuquidar proved to be effective in Phase I/II clinical trials in patients with acute myeloid leukemia (Gerrard et al., 2004) and non-Hodgkin's lymphoma (Morschhauser et al., 2007). Apart from Zosuquidar, at least two other substances, GF120918 and CTB-1, are currently entering Phase II/III clinical trials (Lee, 2010). Recently, there has also been great interest in screening natural products in search for putative chemosensitizers of low toxicity (Teodori et al., 2006; Molnar et al., 2010). Promising candidates have been identified among flavonoids, stilbenoids, coumarins, carotenoids, diterpenes and curcumin derivatives.

While most research groups concentrate their efforts on identifying candidate MDR modulators with the use of such modern approaches as bioinformatics or combinatorial chemistry, voices are being raised that not pharmacological reversal of MDR but rather the avoidance of its emergence is the correct solution to this clinical problem (Higgins, 2007). Especially the importance of the normal tissue-protecting function of P-glycoprotein that may be risky to interfere with is stressed, together with the relative ease of switching on the expression of other types of MDR transporters by chemotherapy-treated cells in response to P-gp blockade.

One of the main problems in successful MDR modulation seems to be the relatively low selectivity of the reversal agents tested against P-glycoprotein (Crowley et al., 2010). Moreover, in contrast to P-gp inhibitors, only a very limited number of MRP1-specific inhibitors have been reported (Sharom, 2008). A same modulator can inhibit both P-glycoprotein and MRP1, some are selectively active towards only one of them, and also the situation when one of the transporters is inhibited and the other stimulated is possible. Therefore simultaneous studying of the activity of the same substances against both main MDR-associated proteins seems important for understanding the molecular mechanism of the modulator-transporter interaction.

In the present review, the interaction of three groups of MDR modulators: phenothiazines, flavonoids and stil- benes with both P-glycoprotein and MRP1 are discussed. Compounds from each group are likely to interact with MDR transporters by diverse mechanisms (see below). Literature data as well as some of our recent results are discussed. Special emphasis is put on cases when interactions of a given compound with both main MDR transporters was studied.

\section{PHENOTHIAZINES}

Phenothiazine derivatives (Fig. 2) are antipsychotics that have been used in the therapy of mental disorders (e.g., schizophrenia) for more than 50 years (Marques et al., 2004). Their postulated mechanism of action is blocking of dopamine receptors (Peroutka \& Snyder, 1980); they have also been found to interact with many ion channels (reviewed in: Michalak et al., 2007). Trifluoperazine (TFP) is also a potent inhibitor of calmodulin (Johnson \& Wittenauer, 1983), protein kinase C (Font et al., 1990) and adenylate cyclase (Doualla-Bell Kotto Maka et al., 1990). Additionally, phenothiazines can strongly influence biophysical properties of one-component lipid bilayers as well as model membranes containing cholesterol-enriched microdomains (Hendrich et al., 2001; Wesolowska et al., 2011).

\section{Interaction of phenothiazines with P-gp}

The ability of TFP to increase the accumulation of cytotoxic drugs in resistant cancer cells was discovered as early as 1982 ('Tsuruo et al., 1982), however, its potency to reverse MDR in P388 mouse leukemia cells varied when different anticancer agents were used (Ganapathi et al., 1984). TFP was one of the first MDR modulators tested in clinical trials, but the outcome was negative since the plasma concentrations of TFP achieved were far too low to be effective (reviewed in: Raderer \& Scheithauer, 1993). Then inhibition of P-glycoprotein transport activity by TFP was confirmed in various cellular models (Ramu \& Ramu, 1992; Leite et al., 2006; Wesolowska et al., 2009a). Other antipsychotic phenothiazines such as chlorpromazine (CPZ) (Ford et al., 1989; Molnar et al., 2003; Wang et al., 2006), thioridazine (TDZ) (Ramu \& Ramu, 1992; Wesolowska et al., 2009a), fluphenazine (Ramu \& Ramu, 1992; Szabo et al., 1999), promethazine (Ford et al., 1989; Motohashi et al., 1997; Molnar et al., 2003) and thiethylperazine (Ramu \& Ramu, 1992; Wesolowska et al., 2009a) have also been demonstrated to impair drug efflux mediated by P-gp.<smiles>c1ccc2c(c1)Nc1ccccc1S2</smiles>

phenothiazine<smiles>CN(C)CCCN1c2ccccc2Sc2ccc(Cl)cc21</smiles><smiles>COCCN1c2ccccc2Sc2ccc(C(F)(F)F)cc21</smiles><smiles>[R]CN(C)c1cccc2c1N(CN)c1ccccc1S2</smiles>

phenothiazine maleates
Figure 2. Chemical structure of phenothiazine derivatives. 
Depending on the model system and the method used for the assessment of anti-MDR activity different phenothiazines were identified as the most potent P-gp inhibitors. Among the antipsychotic phenothiazines studied for MDR reversal in a doxorubicinresistant murine leukemia cell line (P388/ADR) TFP, thiethylperazine, promethazine, and TDZ proved to be the most effective (Ramu \& Ramu, 1992). In a doxorubicin-resistant human breast cancer cell line (MCF-7/ DOX) the highest MDR ratio was recorded for TFP (MDR ratio $=3.4 \pm 0.4)$, fluphenazine $(2.7 \pm 0.3)$, and prochlorperazine $(2.6 \pm 0.4)$ (Ford et al., 1989). The MDR ratio was defined by the authors as the ratio of the $\mathrm{IC}_{50}$ value for doxorubicin to the $\mathrm{IC}_{50}$ for doxorubicin with phenothiazine added in a concentration that alone produced $10 \%$ inhibition of cellular growth. The antipsychotic phenothiazines (tested at $4 \mu \mathrm{g} / \mathrm{ml}$ ) that were identified as the most effective P-gp inhibitors in mouse $\mathrm{T}$ lymphoma cells ectopically expressing human MDR1 gene (L5178 MDR) included thiethylperazine $(F A R=62.1 \pm 11.7)$, TDZ $(56.8 \pm 10.3)$, TFP $(49.2 \pm 9.1)$, and perphenazine $(7.9 \pm 1.3)$ (Wesolowska et al., 2009a). Fluorescence activity ratios (FAR) were defined as the ratios of rhodamine 123 intracellular fluorescence intensity of modulator-treated cell population to the fluorescence intensity of untreated cells.

The phenothiazine scaffold has been subjected to chemical modifications that yielded many new derivatives with significant inhibitory activity against P-glycoprotein (Motohashi et al., 1997; Wesolowska et al., 2002; Barbieri et al., 2003; Konya et al., 2006; Bisi et al., 2008; Schmidt et al., 2008). Effective P-gp inhibitors have been identified among phenothiazine acetylamides, methoxycarbonylamides, and methanesulfonylamides (tested at $40 \mu \mathrm{g} /$ ml) (Wesolowska et al., 2002), as well as among phtalimido- and chloroethylphenothiazines (tested at $20 \mu \mathrm{M}$ ) (Motohashi et al., 1997); the FAR values for the most effective compounds from all groups ranged from 10 to 20. Konya et al. (2006) reported phenothiazine derivatives able to inhibit calcein-AM efflux in MDCK cells ectopically expressing human $M D R 1$ gene with $\mathrm{IC}_{50}$ values below $1 \mu \mathrm{M}$. The most active compound from the group of phenothiazine derivatives bearing a but-2-ynyl amino side chain (tested at $10 \mu \mathrm{M}$ ) was characterized by the MDR ratio for doxorubicin above 7 in two resistant hematological tumor cell lines, HL60R and CEM/ VBL300 (Bisi et al., 2008).

Numerous studies have been performed in order to identify structural features important for phenothiazines to constitute good MDR reversing agents (for a review see Michalak et al., 2006; Tsakovska \& Pajeva, 2006). Analysis of 30 phenothiazines revealed that high MDR reversal activity was displayed by compounds possessing hydrophobic substituent (e.g., $\mathrm{Cl}$ or $\mathrm{CF}_{3}$ ) at position 2 of phenothiazine ring, a four-carbon atom linker between the ring system and the side group and a tertiary (preferably cyclic) amine in the side chain (Ford et al., 1989). The work of Ramu \& Ramu (1992) on more than 200 phenothiazines and related drugs also pointed to the importance of a hydrophobic substituent at position 2 of the ring (however $\mathrm{COCH}_{3}$ and $\mathrm{SOCH}_{3}$ groups were identified as better than $\mathrm{CF}_{3}$ ) and a cyclic tertiary amine in the side chain, additionally the presence of carbonyl groups substituted either on the rings or on the ring-side chain linker was found to increase the anti-MDR activity of phenothiazines. Virtually the same structural elements were identified as important features of effective MDR modulators in several stud- ies conducted on smaller groups of newly-synthesized phenothiazine derivatives (Barbieri et al., 2003; Konya et al., 2006; Bisi et al., 2008; Schmidt et al., 2008). The results of molecular modeling studies of phenothiazines are in general agreement with the results described above. Pajeva and Wiese (1998) pointed to the importance of hydrophobicity of the ring system, type of the substituent at position 2 , and the requirement of some minimal distance between the phenothiazine nucleus and the positively charged side chain. Molecular modeling has also revealed that proper spatial arrangement of hydrophobic (ring, substituent at position 2) and hydrophilic elements (hydrogen bond acceptor) in the phenothiazine molecule is crucial for MDR reversal (Tsakovska, 2003). Additionally, $\mathrm{COC}_{2} \mathrm{H}_{5}$ and $\mathrm{COC}_{3} \mathrm{H}_{7}$ groups and tertiary nitrogen in the piperazine moiety were identified as the most favorable ring substituents and side chain type, respectively. On the other hand, Dearden et al. (2003) in their SAR study failed to correlate the phenothiazine-type modulator's hydrophobicity and spatial arrangement of its hydrogen bond donor/ acceptor groups with its MDR modulatory activity. Instead, molecular size as well as the compound's polarity and polarisability were identified as important factors for MDR reversal by phenothiazine derivatives.

\section{Interaction of phenothiazines with MRP1}

The interaction of phenothiazine derivatives with MRP1 has not been intensively studied. Phenothiazines bear a positive charge at physiological $\mathrm{pH}$ and thus they are not likely to be substrates of MRP1 that preferentially transports anionic or neutral compounds. However, two reports exist in which the influence of phenothiazines on MRP1 transport activity was monitored (Wesolowska et al., 2005a; 2009a). MRP1 is physiologically expressed in human erythrocytes and the test based on monitoring the efflux of a fluorescent carboxyfluorescein derivative (BCPCF) had previously been demonstrated to be indicative of MRP1 activity (Rychlik et al., 2003). Phenothiazine maleates were found to significantly stimulate MRP1-mediated BCPCF transport out of erythrocytes (Wesolowska et al., 2005a). Similar stimulation effects were observed for a group of six commercially available phenothiazines (Wesolowska et al., 2009a). Using both whole erythrocytes and inside-out vesicles prepared from erythrocyte membranes it was demonstrated that the observed effect was due to a stimulation of an active transport system and not to, for example, increased membrane permeability (Wesolowska et al., 2005a). However, it remains to be solved whether the observed stimulatory effect of phenothiazine derivatives is specific only for one substrate (BCPCF) or is a more general phenomenon.

\section{Interaction of phenothiazines with both transporters}

The phenothiazine maleates shown to stimulate MRP1-mediated BCPCF transport out of human erythrocytes (Wesolowska et al., 2005a) had earlier been identified as P-glycoprotein inhibitors in mouse T lymphoma cells transfected with a human MDR1 gene expression construct (Wesolowska et al., 2002; Hendrich et al., 2003b). Their anti-P-gp activity was, however, marginal in the doxorubicin-resistant human uterine sarcoma cell line MES-SA/Dx5 (Wesolowska et al., 2005b). Six commercially available phenothiazines found to stimulate BCPCF efflux were also demonstrated to be effective P-gp inhibitors (Wesolowska et al., 2009a). 
No correlation was noticed between the ability of the phenothiazines to inhibit P-glycoprotein and to stimulate MRP1 (Wesolowska et al., 2005a; 2009a).

\section{Putative mechanism of MDR reversal by phenothiazines}

At present, the molecular mechanism of the phenothiazines' interaction with P-glycoprotein is not understood in detail. Nevertheless, most data suggest that phenothiazine derivatives can bind directly to the protein (Ayesh et al., 1996; Liu \& Sharom, 1996; Safa, 1998; Liu et al., 2000). TFP was demonstrated to bind to the transporter which manifested as quenching of the fluorescence of P-gp tryptophan residues (Liu et al., 2000) as well as external fluorescent probe MIANS (Liu \& Sharom, 1996). TFP was also shown to stimulate P-glycoprotein ATPase activity in plasma membranes isolated from MDR leukemic cells (Shepard et al., 1998). In turn, CPZ was actively transported by P-gp in the same cell model (Syed et al., 1998).

The binding sites for P-gp-interacting drugs are likely to be formed by different regions of the P-gp binding pocket; moreover, binding sites for dissimilar compounds may overlap at least partially (Ambudkar et al., 2006; Crowley \& Callaghan, 2010). Binding of one modulator or substrate can exert various effects on the binding or transport of another one - both positively co-operative and competitive effects have been reported (Ayesh et al., 1996). Taking into account the structural information about the binding pocket of P-gp (see above) it is quite likely that the binding sites for each type of substrate/ modulator are not well separated. Such an assumption is helpful in understanding why the specificity of the putative phenothiazine binding site was described in a dissimilar manner by different research groups. Ayesh et al. (1996) studied the interaction of pairs of modulators with P-gp and concluded that there were two binding sites: one with affinity for TFP and verapamil, and

A

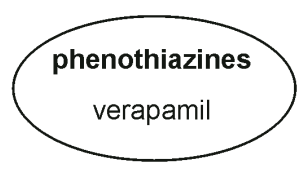

B
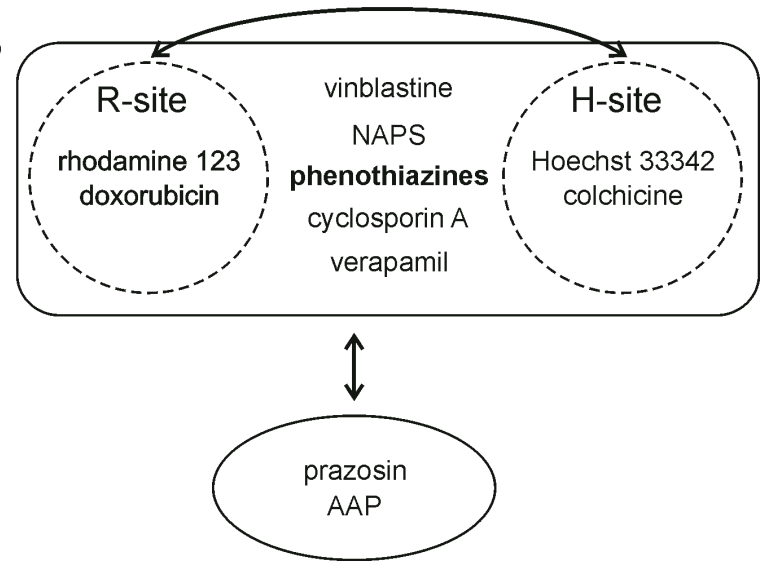

Figure 3. Scheme of putative phenothiazine binding sites on P-gp.

Model suggested by Ayesh et al. and Akiyama et al. (A) and Shapiro \& Ling and Safa et al. (B). Arrows represent positive cooperativity between the sites. See text for detailed description. the second to which vinblastine and tamoxifen bound (Fig. 3A). Similar results were obtained by Akiyama et al. (1988) who demonstrated that TFP, TDZ and CPZ were only weak inhibitors of P-glycoprotein photoaffinity labeling with a vinblastine analog. On the other hand, the most popular two-site model for P-gp proposed by Shapiro and Ling (1997) assumed the existence of Rand $\mathrm{H}$-sites that were positively co-operative (Fig. 3B). Rhodamine 123 and doxorubicin bound to the first site (R-site), Hoechst 33342 and colchicine to the other one (H-site), while vinblastine showed no preference for binding. This model was subsequently supplemented by a third allosteric site interacting with prazosin that stimulated the transport of both rhodamine 123 and Hoechst 33342 (Shapiro et al., 1999) (Fig. 3B). Safa et al. (1994) labeled P-glycoprotein with two photoaffinity probes: prazosin analog AAP and NAPS which was presumed to interact with P-gp at the same site as the anticancer drugs vinblastine, colchicine and doxorubicin. Phenothiazines were shown to compete with NAPS labeling and to stimulate AAP labeling. Further work brought the authors to the conclusion that phenothiazines interacted with P-glycoprotein at the same site where vinblastine, verapamil and cyclosporin A, but not prazosin, were bound (Safa, 1998) (Fig. 3B).

Phenothiazine derivatives are membrane-active compounds (for a review see (Michalak et al., 2006; Michalak et al., 2007)). It has been suggested that their ability to perturb the lipid phase of the cellular membrane may be correlated with their MDR reversal activity (Pajeva et al., 1996). A correlation between P-glycoprotein inhibition and the ability to change biophysical properties of model phospholipid membranes (i.e., transition enthalpy of the bilayer as well as bilayer fluidity) was observed for phenothiazine methoxycarbonylamides and methanesulfonylamides (Hendrich et al., 2003a), but not for phenothiazine maleates (Hendrich et al., 2003b). Bebawy et al. (2001) reported that CPZ reversed resistance to vinblastine in an MDR acute lymphoblastic leukemia cell line but at the same time increased resistance to colchicine. $\mathrm{CPZ}$ was also observed to stimulate fluorescein-colchicine transport in inside-out vesicles prepared form membranes of resistant cells. The authors proposed that the observed effects were due to different membrane localization of the two anticancer agents. CPZ was supposed to stimulate the transport of the drug localized in the same membrane leaflet (inner) as the modulator and to inhibit allosterically the transport of the drug localized in the opposite leaflet.

Little is known about interaction of phenothiazines with MRP1. In the case of the observed stimulation of MRP1-mediated BCPCF efflux out of human erythrocytes it was proposed that phenothiazines interacted directly with the transporter protein at a binding site other than the one occupied by BCPCF and stimulated the efflux of the substrate allosterically (Wesolowska et al., 2005a). Further studies are needed to explain the above observations in detail.

\section{FLAVONOIDS}

Flavonoids constitute the main group of polyphenolic compounds present in human diet and their daily consumption is estimated to be as high as $1 \mathrm{~g}$ (Scalbert \& Williamson, 2000). Their main sources are fruit, vegetables, and plant-derived beverages such as tea, wine or beer. More than 6500 of various flavonoids have been 
described (Harborne \& Williams, 2000). Flavonoids differ mainly by the structure of their ring $C$ (oxidation status and substitution) and they are therefore classified into several subclasses such as flavones, isoflavones, flavonols, flavanols, flavonones, chalcones, etc. (Morris \& Zhang, 2006) (Fig. 4). The list of the beneficial effects exerted by flavonoids on human health is very long. Among others, they have been shown to possess antioxidant, antiviral, anti-carcinogenic, anti-inflammatory, antiestrogenic and estrogen-mimicking activities (reviewed in: Morris \& Zhang, 2006), which may translate to the postulated link between flavonoid consumption and reduced risk of cancer, cardiovascular diseases and osteoporosis. Flavonoids have also been shown to interfere with signal transduction pathways involved in cell proliferation (Na \& Surh, 2006) as well as with cellular detoxification processes (Yu et al., 1997).

In the last 15 years flavonoids, being non-toxic natural products, have attracted attention as putative MDR modulating agents. Their interaction with MDR-associated transporters was the subject of recent reviews (Morris \& Zhang, 2006; Michalak et al., 2007; Alvarez et al., 2010). Here only the most relevant studies are discussed. Particular attention is devoted to the cases when the activity of the same compound was tested simultaneously against the both main MDR transporters.

\section{Interaction of flavonoids with MRP1}

Since the first report on the inhibition of MRP1 by isoflavone genistein (Versantvoort et al., 1993) many flavonoids have been demonstrated to reduce transport activity of MRP1 (including apigenin, baicalein, kaempferol, naringenin, luteolin, morin, quercetin, myricetin, silibin and others) (Hooijberg et al., 1999; Leslie et al., 2001; van Zanden et al., 2005; Wu et al., 2005). Hooijberg et al. (1999) showed that genistein increased accumulation of daunorubicin in a doxorubicin-resistant small-cell lung cancer cell line ca. fourfold as compared to control. Kaempferol was identified as the most potent inhibitor of $\left[{ }^{3} \mathrm{H}\right]$ leukotriene $\mathrm{C}_{4}$ transport in HeLa cells transfected with MRP1 gene construct $\left(K_{\mathrm{i}}=2.4 \pm 1.6 \mu \mathrm{M}\right)$ (Leslie et al., 2001). In studies on the influence of a group of flavonoids on DNP-SG transport by MRP1 luteolin

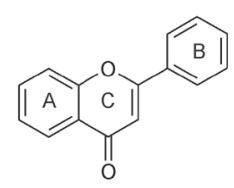

flavone

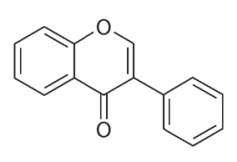

isoflavone<smiles>O=c1c(O)c(-c2ccccc2)oc2ccccc12</smiles>

flavonol

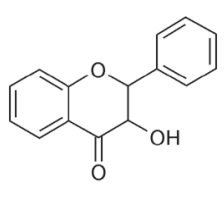

flavanol

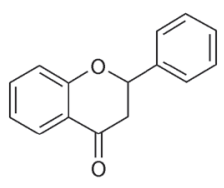

flavanone

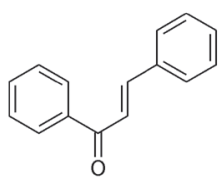

chalcone
Figure 4. Chemical structure of subclasses of flavonoids.
$\left(\mathrm{IC}_{50}=0.8 \pm 0.1 \mu \mathrm{M}\right)$ and taxifolin $(1.3 \pm 0.3 \mu \mathrm{M})$ turned out to be the most effective inhibitors (van Zanden et al., 2004). On the other hand, when the inhibition of calcein efflux from MDCKII cells ectopically expressing human MRP1 gene was monitored methoxylated flavones were identified as the most active compounds (e.g., the $\mathrm{IC}_{50}$ value for diosmetin was $2.7 \pm 0.6 \mu \mathrm{M}$ ), followed by robinetin $(13.6 \pm 3.9 \mu \mathrm{M})$, kaempferol $(19.4 \pm 3.6 \mu \mathrm{M})$, and myricetin $(20.2 \pm 4.3 \mu \mathrm{M})$ (van Zanden et al., 2005). In turn, silymarin proved to be the most effective MDR modulator in MRP1-expressing HEK239 cells (Wu et al., 2005).

Apart from cancer cell lines with MRP1 overexpression induced by drug exposure or transfection with MRP1 gene construct, human erythrocytes have been successfully employed as a model system to demonstrate MRP1 modulating activity of flavonoids (BobrowskaHagerstrand et al., 2003; Lania-Pietrzak et al., 2005; Wesolowska et al., 2009b). The following flavonoids have been shown to be the most potent inhibitors of MRP1mediated efflux of carboxyfluorescein derivatives: sophoraflavanones $\mathrm{A}\left(\mathrm{IC}_{50}=3 \mu \mathrm{M}\right)$ and $\mathrm{H}(7 \mu \mathrm{M})$ (Bobrowska-Hagerstrand et al., 2003); silybin $(5 \pm 0.5 \mu \mathrm{M})$ and morin $(7 \pm 1 \mu \mathrm{M})$ (Lania-Pietrzak et al., 2005); acacetin $(6.5 \pm 4 \mu \mathrm{M})$ (Wesolowska et al., 2009b); as well as 8-prenylnaringenin $(5.7 \pm 1.8 \mu \mathrm{M})$ (Wesolowska et al., 2010a).

Flavonoid structure constitutes also a scaffold for chemical synthesis of new derivatives whose MRP1 modulating activity has already turned out to be very promising. Mavel et al. (2006) obtained a series of flavone derivatives the best of which (tested at $4 \mu \mathrm{M}$ ) was characterized by the MDR ratio for doxorubicin in a resistant $\mathrm{GLC}_{4} / \mathrm{Adr}$ small-cell lung cancer cell line as high as 4.4 (i.e., comparable to the value obtained for the known MRP1 inhibitor MK-571). Newly-synthesized apigenin homodimers also proved to be effective MDR reversal agents (Wong et al., 2009). The most effective compound reached the MDR ratio for doxorubicin of 12.5 (when tested at $0.5 \mu \mathrm{M}$ ).

Interestingly, some observations suggest that under some conditions flavonoids can also stimulate MRP1mediated transport. Versantvoort et al. (1996) found that genistein, daidzein and quercetin inhibited daunorubicin transport but stimulated the transport of rhodamine 123 in lung cancer cells. The dissimilar activity of flavonoids in relation to the transport of different substrates was also reported by Nguyen et al. (2003) in human adenocarcinoma cell line Panc-1. The majority of 22 flavonoids studied increased intracellular accumulation of both daunorubicin and vinblastine, however, apigenin, galangin, luteolin and rhoifolin were inhibitors of vinblastine transport but stimulators for daunorubicin. Fisetin and myricetin stimulated the efflux of both substrates, while naringenin decreased the accumulation of vinblastine but not of daunorubicin.

Attempts have also been made to draw some structure-activity relationships for flavonoids as MRP1 modulators (van Zanden et al., 2004; 2005). When a set of 11 compounds (belonging to different flavonoid subclasses but bearing no other ring substituents than hydroxyl groups) was analyzed two features have been identified that increased the potency of flavonoids to inhibit MRP1 (van Zanden et al., 2004). These were the presence of two hydroxyl groups at positions 3' and 4' of ring B (that generated the catechol moiety), and the planarity of the molecule provided by the existence of $\mathrm{C} 2-\mathrm{C} 3$ double bond. The molecule's lipophilicity and the total number of hydroxyl groups proved to be less important. When 
the group of the studied flavonoids was increased a different set of parameters was obtained, including: i) total number of methoxylated moieties; ii) total number of hydroxyl groups; and iii) the dihedral angle between the Band C-ring (van Zanden et al., 2005). Additionally, LaniaPietrzak et al. (2005) pointed to the importance of a hydrophobic substituent at position 4' of ring B for high MRP1 inhibitory activity of flavonoids. The presence of a large hydrophobic substituent (e.g., prenyl, geranyl, or lavandulyl group) at position 8 of ring $\mathrm{A}$ was also reported to increase the potency of these compounds to inhibit MRP1 (Bobrowska-Hagerstrand et al., 2003).

\section{Interaction of flavonoids with P-gp}

The search for effective P-glycoprotein inhibitors among flavonoids has been very intense lately (Zhang \& Morris, 2003; Kitagawa et al., 2005; Chung et al., 2005; Sheu et al., 2010; Zhang et al., 2010). Among many others acacetin, galangin, myricetin, morin, biochanin $\mathrm{A}$, and kaempferol have been identified to be P-glycoprotein inhibitors. Kitagawa et al. (2005) showed that kaempferol (at $100 \mu \mathrm{M}$ ) increased rhodamine 123 accumulation in P-gP overexpressing KB-C2 cells more than twofold. Biochanin A and silymarin (tested at $100 \mu \mathrm{M}$ ) exhibited high MDR ratios for daunomycin in resistant human breast cancer cell line MCF-7/ADR (3.7 and 2.5, respectively) (Chung et al., 2005). When accumulation of daunorubicin in the same cell line was studied biochanin A, phloretin, morin, and silymarin (tested at $100 \mu \mathrm{M}$ ) were identified as the most active (Zhang et al., 2010). An over three-fold increase of fexofenadine accumulation by $\mathrm{P}$-gp-expressing human colorectal adenocarcinoma HTC-15 cells was obtained when galangin, baicalein, or hesperidin were applied at the $100 \mu \mathrm{M}$ concentration. It should be noted, however, that the data on P-gp modulation by flavonoids are very context dependent, i.e., different results were observed by different authors depending mainly on the cellular model and substrate used to assess P-gp inhibition by flavonoids. Especially, compounds that were weakly active or non-active in one experimental setting tend to show slight stimulatory activity on P-gp function in other settings (compare, e.g., the results for genistein in Zhang et al. (2010) and Sheu et al. (2010), as well as for quercetin in Chung et al. (2005) and Sheu et al. (2010)).

There are also several studies demonstrating significant stimulation of P-glycoprotein transport function by flavonoids. Phang et al. (1993) observed increased efflux of the carcinogen 7,12-dimethylbenz(a)-anthracene from P-gp-expressing breast cancer cells in the presence of kaempferol, quercetin or galangin. The same flavonoids as well as apigenin, fisetin, rutin, and genistein were shown to decrease intracellular accumulation of doxorubicin and to reduce its cytotoxicity to HTC-15 colon cells (Critchfield et al., 1994). This effect was abrogated by the P-gp inhibitor verapamil. The ability of isoflavones genistein and daidzein to stimulate rhodamine 123 efflux was also observed in vinblastine-resistant colon carcinoma cells (Okura et al., 2010). The stimulatory effect of flavonoids on P-glycoprotein may be, however, substrate-dependent. Chieli et al. (1995) observed the ability of kaempferol, galangin and quercetin to inhibit the efflux of rhodamine 123 from rat hepatocytes while stimulating the efflux of doxorubicin. Similar substratedependent observations for green tea catechins made Wang et al. (2002) propose that flavonoids could allosterically modulate P-glycoprotein transport. The above communications indicate the notion that unmodified flavonoids should be regarded as P-glycoprotein modulators rather than inhibitors, since they can either up-regulate or reduce its function.

Flavonoids have been subjected to various chemical modifications in order to obtain better P-glycoprotein inhibitors (Chan et al., 2006; Dzubak et al., 2006). In general, it was found that modifications that increased hydrophobicity of the molecule such as prenylation or geranylation significantly increased the modulatory activity of flavonoids (Di Pietro et al., 2002). According to this observation, 8-prenylnaringenin turned out to be an effective inhibitor of rhodamine 123 transport in human adenocarcinoma cells (Wesolowska et al., 2010a). Additionally, methoxyflavones have recently attracted noticeable attention due to their high activity as P-glycoprotein inhibitors (Choi et al., 2004; Ohtani et al., 2007).

The structure-activity relationships for flavonoids as P-gp modulators have been intensively studied in recent years. In their study on inhibition of P-gp-mediated transport by 22 flavonoids from four subclasses (Sheu et al., 2010) suggested that the presence of hydroxyl groups at position 7 of ring $A$ and at position 5' of ring $B$ as well as the C2-C3 double bond of ring $\mathrm{C}$ were favorable for inhibitory activity. The presence of hydroxyl groups, planar molecule's structure, and hydrophobicity were identified as important parameters for the ability of tea cetechins to affect rhodamine 123 accumulation in Pgp-overexpressing KB-C2 cells (Kitagawa et al., 2006). On the other hand, Choi et al. (2004) stressed that the number and localization of methoxy groups could influence the P-gp-modulating activity of flavonoids to a greater extent than the number and position of hydroxyl groups. Many studies have been performed in which the affinity of flavonoids for binding to the C-terminal NBD (NBD2) of P-gp was examined (for a review see: Boumendjel et al., 2002; Di Pietro et al., 2002). SAR analyses performed with the use of data obtained in this model system showed that the affinity for NBD2 binding decreased in the order: dehydrosilybin $>$ chalcone $>$ flavonol $>$ flavone $>$ isoflavone $>$ flavanone (Di Pietro et al., 2002). Additionally, the role of the hydrophobicity of ring substituents was stressed since compounds containing geranyl groups were more active than the ones substituted by halogen atoms, followed by flavonoids with methoxy and hydroxyl groups. In summary, flavonoids with high affinity for NBD2 of P-gp should possess $\mathrm{OH}$ groups at positions 3 and 5 of ring $\mathrm{A}$, a carbonyl group at position 4, C2-C3 double bond, and finally a hydrophobic motif on either ring A or B (Boumendjel et al., 2002). Molecular modeling studies performed on the above set of biological data pointed to steric parameters and hydrophobicity as major physicochemical parameters governing flavonoids' binding to NBD2 (especially the presence of hydrophobic substituents at positions 6 and 8 of ring $\mathrm{A}$ was stressed), while the hydrogen-bonding capacity was a minor modulator (Boccard et al., 2009, Kothandan et al., 2011).

\section{Interaction of flavonoids with both transporters}

Although the literature dealing with MDR modulation by flavonoids is vast, reports in which the anti-PgP and anti-MRP1 potency of the same group of compounds was tested simultaneously are relatively scarce. Katayama et al. (2007) tested the inhibitory activity of 11 flavones and flavonols against P-glycoprotein and MRP1 in cancer cell lines transfected with the respective gene constructs. Only acacetin and 3,,4',7-trimeth- 
oxyflavone were found to be relatively weak inhibitors of P-gp, while none of the compounds affected the activity of MRP1. The influence of 16 flavonoids on the transport of fluorescent substrates BCECF and rhodamine 123 by MRP1 and P-gp, respectively, was studied by Gyemant et al. (2005). Inhibitors of both P-gp and MRP1 transporters were identified (chrysin, robinin, epigallocatechin), as well as selective inhibitors of only one $\mathrm{ABC}$ protein (e.g., kaempferol inhibited only MRP1, while naringin and floretin only P-gp). Some cases in which the function of one of the transporters was stimulated were also noted (e.g., rotenone and catechin stimulated MRP1 and inhibited P-gp). In turn, two flavones (apigenin and acacetin) and two flavonols (morin and myricetin) have been shown to be potent inhibitors of MRP1-mediated efflux of fluorescent substrate BCECF in human erythrocytes (Wesolowska et al., 2009b). Their activity to inhibit the transport of the same substrate in resistant breast cancer cells was, however, much lower. This discrepancy was most probably due to the different characteristics of the two cellular models (e.g., different MRP1 levels). None of the studied compounds turned out to inhibit P-glycoprotein (Wesolowska et al., 2009b). On the other hand, Nabekura et al. (2008) demonstrated that a naturally occurring methoxylated flavone — nobiletin — was an effective inhibitor of both main MDR-associated transporters. Among a group of six polymethoxyflavones isolated from the rhizome of the Thai medicinal plant Kaempferia parviflora two inhibitors of both transporters were identified, while two compounds inhibited only MRP1 (Patanasethanont et al., 2007a; 2007b). Another example of a flavonoid reducing the transport activity of both P-glycoprotein and MRP1 is 8-prenylnaringenin (Wesolowska et al., 2010a). In spite of its inhibitory activity, 8-prenylnaringenin was unable to restore sensitivity to doxorubicin in resistant human adenocarcinoma cell line LoVo/Dx. That was probably due to the involvement of other — non-P-gp-dependent — mechanisms of resistance in that cell line.

\section{Putative mechanism of MDR reversal by flavonoids}

The mechanism of flavonoid interaction with MDR transporters is believed to involve their binding to the cytosolic NBD domains (Conseil et al., 1998; Trompier et al., 2003). This was first proposed by Conseil et al. (1998) on the basis of experiments that showed direct binding of simple flavones, isoflavones and flavanones to the purified cytosolic NBD from mouse P-glycoprotein. Such experiments were also conducted for other flavonoids demonstrating their high affinity to nucleotide-binding domains of P-gp (reviewed in (Boumendjel et al., 2002)). It has also been proposed that the site of interaction for more hydrophobic flavonoid derivatives was shifted outside of the ATP site, probably to the vicinal steroid binding site on NBD or even to a region within the TMD domain of P-glycoprotein (Di Pietro et al., 2002). A similar mechanism was also proposed for the flavonoid-MRP1 interaction (Trompier et al., 2003).

On the other hand, flavonoids do not block ATP hydrolysis by MDR transporters. Their influence on the ATPase activity of MRP1 can be stimulatory, inhibitory or biphasic (stimulation at low modulator concentrations and inhibition at high concentrations) depending on the flavonoid tested (Leslie et al., 2003; Wu et al., 2005). Flavonoids were also reported not to interfere with MRP1 labeling by a photoactivable ATP analog (Wu et al., 2005).
The varied influence of flavonoids on transport of different substrates by MDR proteins (Chieli et al., 1995; Versantvoort et al., 1996), their ability to inhibit competitively the transport of leukotriene $\mathrm{C}_{4}$ by MRP1 (Leslie et al., 2003), as well as to stimulate GSH transport (Leslie et al., 2001) point to possible interactions of at least some flavonoids with drug binding sites of MDRassociated transporters. This supposition is consistent with the results of P-glycoprotein photolabeling with substrate analogs that was inhibited by genistein (Castro \& Altenberg, 1997), morin (Leslie et al., 2003) and green tea polyphenols (Jodoin et al., 2002). Additionally, some flavonoids have been demonstrated to be substrates of MDR-associated transporters (Wang et al., 2005, Tian et al., 2006).

The question of a putative indirect influence of flavonoids on MRP1 transport activity by perturbation of lipid membrane was addressed by Wesolowska et al. (2009b). No clear relationship was found between the MRP1-inhibitory potency of flavonoids and their ability to change phase transition parameters of lipid bilayers (temperature and enthalpy) and to quench the fluorescence of two fluorescent probes of distinct membrane localization. Additionally, no correlation between $\log \mathrm{P}$ value of the flavonoid and its biological activity was noticed. Also van Zanden et al. (2005) found no correlation between lipophilicity of the flavonoids studied and their ability to inhibit MRP1.

In summary, flavonoids can interact with NBD domains of both P-glycoprotein and MRP1. Their interaction with the drug binding domains of $\mathrm{ABC}$ proteins cannot be, however, excluded. In general, flavonoids seem to be quite a heterogenic group and the mechanisms of MDR modulation by individual compounds may be distinct.

\section{STILBENES}

Stilbenes are secondary metabolites of a variety of plants, synthesized either constitutively or in response to environmental stress (Roupe et al., 2006). The stressinduced stilbenes are often named phytoalexins (plant antibiotics) and their main function is believed to be the defense of the host organism against viral, microbial or fungal attack. Stilbenes are stereoisomers and may exist either in the $Z$ (trans) or in $E$ (cis) form (Fig. 5); the majority of the naturally occurring stilbenes are trans isomers. The two forms seem to possess different pharmacological activities (Roupe et al., 2006). Several stilbenes have been isolated and characterized including pinosylvin, pterostilbene, piceatannol and resveratrol. The pharmacological activity of the latter compound is undoubtedly best characterized. Additionally, tamoxifen, a tissue-selective antagonist of the estrogen receptor used in therapy of breast cancer, is a synthetically obtained stilbene derivative. On the basis of the current phytochemical knowledge one can expect that many more stilbene compounds await identification.

Resveratrol (3,5,4'-trihydroxy-trans-stilbene) is a product of the grapevine Vitis vinifera and its main sources in human diet are grapes, red wine and peanuts (Signorelli \& Ghidoni, 2005). After consumption resveratrol is metabolized by cytochrome P450 enzymes and its major metabolite piceatannol (3,5,3',4'-tetrahydroxy-transstilbene) is formed in the liver (Potter et al., 2002). Both compounds display a wide range of biological activities (for a review see: Baur \& Sinclair, 2006; Roupe et al., 


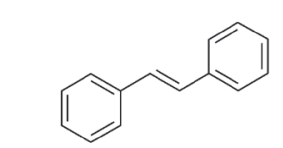

trans-stilbene<smiles>Oc1ccc(/C=C/c2cc(O)cc(O)c2)cc1</smiles>

resveratrol<smiles>Oc1cc(O)cc(C=Cc2ccc(O)c(O)c2)c1</smiles>

piceatannol

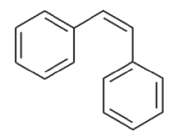

cis-stilbene
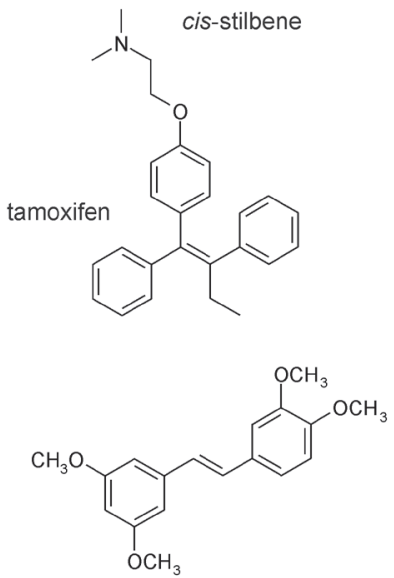

3,5,3',4'-tetramethoxy-trans-stilbene
Figure 5. Chemical structure of stilbene derivatives.

2006; Pirola \& Frojdo, 2008). These include anti-inflammatory, estrogenic, and neuroprotective properties, as well as inhibition of angioneogenesis, regulation of gene expression, cell cycle and apoptosis. Resveratrol is also known to possess significant antioxidant activity (Fabris et al., 2008) and to intercalate into the headgroup region of lipid bilayers (Wesolowska et al., 2009c). Moderate consumption of red wine that can contain a few milligrams of resveratrol per liter (Faustino et al., 2003) is also believed to be responsible, at least in part, for the so called "French paradox" (Baur \& Sinclair, 2006), i.e., reduced risk of coronary heart disease in spite of a high-fat diet. The protection against heart diseases was attributed to the ability of resveratrol to prevent platelet aggregation together with its antioxidative properties and the influence on vasodilation and cholesterol metabolism. Additionally, resveratrol is perceived as a promising candidate for a chemopreventive agent since it was observed to affect tumor initiation, promotion and progression (Baur \& Sinclair, 2006). These activities in combination with the relatively low toxicity of resveratrol arouse hope for its potential prophylactic use.

\section{Interaction of stilbenes with P-gp}

Stilbenes that were the most intensively studied in MDR cells characterized by P-glycoprotein expression are tamoxifen and resveratrol. Tamoxifen has been recognized as an effective MDR reversal agent able to sensitize resistant breast cancer cells to doxorubicin (De Vincenzo et al., 1996). Its activity has been shown, however, to result neither from its ability to inhibit P-glycoprotein nor to down-regulate its expression. Instead, it was related to the ability of tamoxifen to block the cell cycle by arresting cells at the G2/M phase.

Resveratrol (tested at $200 \mathrm{nM}$ ) was also demonstrated to sensitize resistant human oral epidermoid carcinoma cell line KBv200 to vincristine (MDR ratio = 7.7), doxorubicin (5.8) and paclitaxel (6.1) (Quan et al., 2008). Its influence on P-gp transport function was not studied and the MDR reversing activity was attributed to inhibition of MDR1 gene expression as well as to promotion of cell apoptosis. On the other hand, resveratrol has recently been identified as a moderately active inhibitor of transport of daunorubicin and rhodamine 123 by P-glycoprotein both in human epidermoid carcinoma KB-C2 cells (Nabekura et al., 2005) and in doxorubicin-resistant breast cancer cell line MCF-7/ADR (Choi et al., 2009).

The number of studies on MDR modulation by piceatannol and its derivatives is very limited. Ferreira et al. (2006) investigated piceatannol and its derivatives in which different number of hydroxyl groups had been methylated. One of the compounds, 3,5,3',4'-tetramethoxy-trans-stilbene turned out to be a potent inhibitor of rhodamine 123 efflux carried out by P-gp (FAR =56 at the modulator concentration of $4 \mu \mathrm{g} / \mathrm{ml}$ ). It also sensitized an MDR1 gene-transfected mouse $\mathrm{T}$ lymphoma cell line as well as resistant human breast cancer cell line $\mathrm{MCF}-7 / \mathrm{KCR}$ to doxorubicin. The MDR-reversing activity of resveratrol, piceatannol and its two synthetic derivatives has additionally been studied in drug-sensitive and doxorubicin-resistant human adenocarcinoma cell lines, LoVo and LoVo/Dx (Wesolowska et al., 2010b). One MDR modulator that was effective in the resistant cell line was identified - 3,5,3',4'-tetramethoxy-trans-stilbene $(F A R=4.8$ at the modulator concentration of 100 $\mu \mathrm{M})$. This compound not only inhibited P-gp-mediated rhodamine 123 transport, but also significantly increased doxorubicin accumulation inside resistant cells and sensitized them to the anticancer drug.

\section{Interaction of stilbenes with MRP1}

The ability of stilbenes to interact with MRP1 has not been extensively explored. Wu et al. (2005) found resveratrol to be ineffective in increasing calcein accumulation in an MRP1-expressing cell line. Resveratrol was also shown not to influence MRP1-mediated efflux of fluorescent substrate BCPCF out of human erythrocytes (Bobrowska-Hagerstrand et al., 2006). In the same study piceatannol was identified to inhibit transport function of MRP1 with moderate activity $\left(\mathrm{IC}_{50}=57 \pm 9.5 \mu \mathrm{M}\right)$, while resveratrol oligomers were potent MRP1 inhibitors $\left(\mathrm{IC}_{50}\right.$ for sophorastilbene $\mathrm{A}$ was $3.1 \pm 1.0 \mu \mathrm{M}$, and for $(+)$ - $\alpha$-viniferin $0.8 \pm 0.1 \mu \mathrm{M})$. Similar results for piceatannol were obtained in the work of Wesolowska et al. (2007), in which two new piceatannol derivatives were additionally investigated. The MRP1 inhibition by 3,5,3',4'-tetramethoxy-trans-stilbene was very low but 3,5,3',4'-tetraacetoxy-trans-stilbene turned out to be an effective inhibitor of fluorescent substrate efflux out of erythrocytes. In a recent study Kweon et al. (2010) have demonstrated the ability of resveratrol to reverse the resistance to doxorubicin in an MRP1-expressing acute myeloid leukemia cell line. This effect was, however, attributed to resveratrol-induced down-regulation of MRP1 expression and not to the interference of the stilbene with the protein's transport function.

\section{Interaction of stilbenes with both transporters}

The influence of resveratrol, piceatannol and its two derivatives on transport function of both MRP1 (Wesolowska et al., 2007) and P-glycoprotein (Wesolowska et al., 2010b) has been studied. None of the piceatannol-based compounds that had been identified as MRP1 inhibitors turned out to interfere with P-glycoprotein function. On the other hand, the only P-gp inhibitor identified (3,5,3',4'-tetramethoxy-trans-stilbene) interacted with MRP1 only very weakly. This suggests that the correct design of the side substituents attached to piceatannol scaffolding may yield derivatives selectively interact- 
ing either with P-gp or MRP1, but the low number of compounds studied precludes any definite conclusions.

\section{Putative mechanism of MDR reversal by stilbenes}

The mechanism of the interaction of stilbenes with MDR-associated transporters is poorly understood. Callaghan \& Higgins (1995) demonstrated that tamoxifen interfered with P-glycoprotein photolabeling by substrate analogs and increased vinblastine accumulation in P-gpexpressing cells without being a transported substrate itself. Moreover, resveratrol was reported to reduce photolabeling of P-gp by ${ }^{125}$ $]$ iodoarylazidoprazosin by $40 \%$ in resistant Chinese hamster ovary cells $\left(\mathrm{CH}^{\mathrm{R}} \mathrm{C} 5\right)$ (Jodoin et al., 2002). These observations together with the stilbene structure (two aromatic rings connected by a relatively flexible linker) point to putative interaction of these compounds with the drug binding sites on Pglycoprotein and, presumably, also on MRP1. Future studies are, however, needed to fully elucidate this problem. Also other putative mechanisms of MDR reversal activity of stilbenes should be taken into consideration, such as their influence on gene expression and interference with apoptotic pathways.

\section{CONCLUDING REMARKS}

Studies of multidrug resistance modulators, despite having produced no clinically beneficial results yet, have already greatly improved our knowledge about the MDR-associated transporters and molecular mechanisms of their action, especially the process of substrate and/or inhibitor recognition. In the present review the interaction of P-glycoprotein and MRP1 with three groups of MDR modulators was discussed. Each of the groups appears to interact with the transporters via unique mechanism. Phenothiazines most probably directly bind with the protein's substrate recognition sites, although perturbation of the lipid bilayer and indirect influence on transporter activity cannot be excluded. The primary site of interaction of flavonoids with $\mathrm{ABC}$ proteins is likely to be within their nucleotide-binding domains, though the more hydrophobic flavonoids may also interact with regions within the transmembrane domains. The possible mechanism of MDR reversal by stilbenes seems to result from their direct interaction with the transporter (possibly within substrate binding sites) but some nontransporter effects such as changes in gene expression pattern and interference of stilbenes with apoptotic pathways should also be considered.

A comparison of the interaction of the modulators from each group with the two main MDR transporters also brings some interesting insights. Phenothiazines that have long been recognized as potent P-glycoprotein inhibitors turned out to be stimulators of MRP1 transport activity (Wesolowska et al., 2005a; 2009a). Whether this phenothiazine-induced stimulation is a general effect or only a substrate-specific one remains to be discovered. Flavonoids appear to be not exactly inhibitors of MDR transporters but rather their modulators. Among simple, unsubstituted flavonoids very strong inhibitors of either P-glycoprotein or MRP1 can seldom be found; flavonoids may both reduce and stimulate transport activity of P-gp and MRP1. Nevertheless, chemical modifications of the flavonoid scaffold have many times yielded modulators of improved affinity and selectivity towards one of the MDR transporters. Flavonoids bearing hydrophobic substituents deserve particular attention since they tend to be effective inhibitors of both transporters (Di Pietro et al., 2002; Wesolowska et al., 2010a). Stilbenes seem to be selectively active against either P-gp or MRP1 (Wesolowska et al., 2007; 2010b), however, the low number of the derivatives studied precludes definitive conclusions.

In any case, continuing studies on multidrug resistance reversal by different compounds should improve our understanding of MDR transporters and bring us closer to the practical solution of this great clinical problem.

\section{Acknowledgements}

This work was financed by the Ministry of Science and Higher Education funds for Wroclaw Medical University.

\section{REFERENCES}

Akiyama S, Cornwell MM, Kuwano M, Pastan I, Gottesman MM (1988) Most drugs that reverse multidrug resistance also inhibit photoaffinity labeling of P-glycoprotein by a vinblastine analog. Mol Pharmacol 33: 144-147.

Aller SG, Yu J, Ward A, Weng Y, Chittaboina S, Zhuo R, Harrell PM, Trinh YT, Zhang Q, Urbatsch IL, Chang G (2009) Structure of Pglycoprotein reveals a molecular basis for poly-specific drug binding. Science 323: 1718-1722.

Alvarez AI, Real R, Perez M, Mendoza G, Prieto JG, Merino G (2010) Modulation of the activity of ABC transporters (P-glycoprotein, MRP2, BCRP) by flavonoids and drug response. J Pharm Sci 99: 598-617.

Ambudkar SV, Dey S, Hrycyna CA, Ramachandra M, Pastan I, Gottesman MM (1999) Biochemical, cellular, and pharmacological aspects of the multidrug transporter. Annu Rev Pharmacol Toxicol 39: 361398.

Ambudkar SV, Kim IW, Sauna ZE (2006) The power of the pump: Mechanisms of action of P-glycoprotein (ABCB1). Eur J Pharm Sci 27: 392-400.

Ayesh S, Shao YM, Stein WD (1996) Co-operative, competitive and non-competitive interactions between modulators of P-glycoprotein. Biochim Biophys Acta 1316: 8-18.

Barbieri F, Alama A, Tasso B, Boido V, Bruzzo C, Sparatore F (2003) Quinolizidinyl derivatives of iminodibenzyl and phenothiazine as multidrug resistance modulators in ovarian cancer cells. Invest New Drugs 21: 413-420.

Baur JA, Sinclair DA (2006) Therapeutic potential of resveratrol: the in vivo evidence. Nat Rev Drug Discov 5: 493-506.

Bebawy M, Morris MB, Roufogalis BD (2001) Selective modulation of P-glycoprotein-mediated drug resistance. Br J Cancer 85: 1998-2003.

Beck WT (1984) Cellular pharmacology of Vinca alkaloid resistance and its circumvention. Adv Enzyme Regul 22: 207-227.

Bisi A, Meli M, Gobbi S, Rampa A, Tolomeo M, Dusonchet L (2008) Multidrug resistance reverting activity and antitumor profile of new phenothiazine derivatives. Bioorg Med Chem 16: 6474-6482.

Bobrowska-Hagerstrand M, Wrobel A, Mrowczynska L, Soderstrom T, Shirataki Y, Motohashi N, Molnar J, Michalak K, Hagerstrand H (2003) Flavonoids as inhibitors of MRP1-like efflux activity in human erythrocytes. A structure-activity relationship study. Oncol Res 13: $463-469$.

Bobrowska-Hagerstrand M, Lillas M, Mrowczynska L, Wrobel A, Shirataki Y, Motohashi N, Hagerstrand H (2006) Resveratrol oligomers are potent MRP1 transport inhibitors. Anticancer Res 26: 2081-2084.

Boccard J, Bajot F, Di Pietro A, Rudaz S, Boumendjel A, Nicolle E, Carrupt PA (2009) A 3D linear solvation energy model to quantify the affinity of flavonoid derivatives toward P-glycoprotein. Eur J Pharm Sci 36: 254-264.

Borst P, Zelcer N, van de Wetering K, Poolman B (2006) On the putative co-transport of drugs by multidrug resistance proteins. FEBS Lett 580: 1085-1093.

Boumendjel A, Di Pietro A, Dumontet C, Barron D (2002) Recent advances in the discovery of flavonoids and analogs with high-affinity binding to P-glycoprotein responsible for cancer cell multidrug resistance. Med Res Rev 22: 512-529.

Broccatelli F, Carosati E, Neri A, Frosini M, Goracci L, Oprea TI, Cruciani G (2011) A novel approach for predicting P-glycoprotein (ABCB1) inhibition using molecular interaction fields. I Med Chem 54: 1740-1751.

Callaghan R, Higgins CF (1995) Interaction of tamoxifen with the multidrug resistance P-glycoprotein. Br J Cancer 71: 294-299. 
Campbell JD, Koike K, Moreau C, Sansom MS, Deeley RG, Cole SP (2004) Molecular modeling correctly predicts the functional importance of Phe594 in transmembrane helix 11 of the multidrug resistance protein, MRP1 (ABCC1). I Biol Chem 279: 463-468.

Castro AF, Altenberg GA (1997) Inhibition of drug transport by genistein in multidrug-resistant cells expressing P-glycoprotein. Biochem Pharmacol 53: 89-93.

Chan KF, Zhao Y, Burkett BA, Wong IL, Chow LM, Chan TH (2006) Flavonoid dimers as bivalent modulators for P-glycoprotein-based multidrug resistance: synthetic apigenin homodimers linked with defined-length poly(ethylene glycol) spacers increase drug retention and enhance chemosensitivity in resistant cancer cells. J Med Chem 49: 6742-6759.

Chieli E, Romiti N, Cervelli F, Tongiani R (1995) Effects of flavonols on P-glycoprotein activity in cultured rat hepatocytes. Life Sci 57: 1741-1751.

Choi CH, Kim JH, Kim SH (2004) Reversal of P-glycoprotein-mediated MDR by 5,7,3',4',5'-pentamethoxyflavone and SAR. Biochem Biophys Res Commun 320: 672-679.

Choi JS, Choi BC, Kang KW (2009) Effect of resveratrol on the pharmacokinetics of oral and intravenous nicardipine in rats: possible role of P-glycoprotein inhibition by resveratrol. Pharmazie 64: 49-52.

Choudhuri S, Klaassen CD (2006) Structure, function, expression, genomic organization, and single nucleotide polymorphisms of human ABCB1 (MDR1), ABCC (MRP), and ABCG2 (BCRP) efflux transporters. Int J Toxicol 25: 231-259.

Chung SY, Sung MK, Kim NH, Jang JO, Go EJ, Lee HJ (2005) Inhibition of P-glycoprotein by natural products in human breast cancer cells. Arch Pharm Res 28: 823-828.

Cole SP, Bhardwaj G, Gerlach JH, Mackie JE, Grant CE, Almquist KC, Stewart AJ, Kurz EU, Duncan AM, Deeley RG (1992) Overexpression of a transporter gene in a multidrug-resistant human lung cancer cell line. Science 258: 1650-1654.

Conseil G, Baubichon-Cortay H, Dayan G, Jault JM, Barron D, Di Pietro A (1998) Flavonoids: a class of modulators with bifunctional interactions at vicinal ATP- and steroid-binding sites on mouse Pglycoprotein. Proc Natl Acad Sci USA 95: 9831-9836.

Critchfield JW, Welsh CJ, Phang JM, Yeh GC (1994) Modulation of adriamycin accumulation and efflux by flavonoids in HCT-15 colon cells. Activation of P-glycoprotein as a putative mechanism. Biochem Pharmacol 48: 1437-1445.

Crowley E, Callaghan R (2010) Multidrug efflux pumps: drug binding — gates or cavity? FEBS J 277: 530-539.

Crowley E, McDevitt CA, Callaghan R (2010) Generating inhibitors of P-glycoprotein: where to, now? Methods Mol Biol 596: 405-432.

De Vincenzo R, Scambia G, Benedetti Panici P, Fattorossi A, Bonanno G, Ferlini C, Isola G, Pernisco S, Mancuso S (1996) Modulatory effect of tamoxifen and ICI 182,780 on adriamycin resistance in MCF-7 human breast-cancer cells. Int J Cancer 68: 340-348.

Dean M (2005) The genetics of ATP-binding cassette transporters. Methods Ensymol 400: 409-429.

Dearden JC, Al-Noobi A, Scott AC, Thomson SA (2003) QSAR studies on P-glycoprotein-regulated multidrug resistance and on its reversal by phenothiazines. SAR QSAR Environ Res 14: 447-454.

Deeley RG, Cole SP (2006) Substrate recognition and transport by multidrug resistance protein 1 (ABCC1). FEBS Lett 580: 1103-1111.

Dey S, Ramachandra M, Pastan I, Gottesman MM, Ambudkar SV (1997) Evidence for two nonidentical drug-interaction sites in the human P-glycoprotein. Proc Natl Acad Sci USA 94: 10594-10599.

Di Pietro A, Conseil G, Perez-Victoria JM, Dayan G, Baubichon-Cortay H, Trompier D, Steinfels E, Jault JM, de Wet H, Maitrejean M, Comte G, Boumendjel A, Mariotte AM, Dumontet C, McIntosh DB, Goffeau A, Castanys S, Gamarro F, Barron D (2002) Modulation by flavonoids of cell multidrug resistance mediated by P-glycoprotein and related ABC transporters. Cell Mol Life Sci 59: 307-322.

Doualla-Bell Kotto Maka F, Breuiller M, Leroy MJ, Josserand S, Ferre F (1990) Sensitivity of the human myometrial adenylate cyclase to calcium and calmodulin. Gynecol Obstet Invest 30: 169-173.

Dzubak P, Hajduch M, Gazak R, Svobodova A, Psotova J, Walterova D, Sedmera P, Kren V (2006) New derivatives of silybin and 2,3-dehydrosilybin and their cytotoxic and P-glycoprotein modulatory activity. Bioorg Med Chem 14: 3793-3810.

Evers R, de Haas M, Sparidans R, Beijnen J, Wielinga PR, Lankelma J, Borst P (2000) Vinblastine and sulfinpyrazone export by the multidrug resistance protein MRP2 is associated with glutathione export. Br J Cancer 83: 375-383.

Eytan GD, Regev R, Oren G, Assaraf YG (1996) The role of passive transbilayer drug movement in multidrug resistance and its modulation. J Biol Chem 271: 12897-12902.

Fabris S, Momo F, Ravagnan G, Stevanato R (2008) Antioxidant properties of resveratrol and piceid on lipid peroxidation in micelles and monolamellar liposomes. Biophys Chem 135: 76-83.

Faustino RS, Sobrattee S, Edel AL, Pierce GN (2003) Comparative analysis of the phenolic content of selected Chilean, Canadian and American Merlot red wines. Mol Cell Biochem 249: 11-19.
Ferreira MJ, Duarte N, Gyemant N, Radics R, Cherepnev G, Varga A, Molnar J (2006) Interaction between doxorubicin and the resistance modifier stilbene on multidrug resistant mouse lymphoma and human breast cancer cells. Anticancer Res 26: 3541-3546.

Fojo A, Hamilton TC, Young RC, Ozols RF (1987) Multidrug resistance in ovarian cancer. Cancer 60: 2075-2080.

Font J, Marino A, Ravelingien N, Dehaye JP, Trueba M, Macarulla JM (1990) Calcium-activated, phospholipid-dependent protein kinase activity in calf platelets. Rev Esp Fisiol 46: 325-330.

Ford JM, Prozialeck WC, Hait WN (1989) Structural features determining activity of phenothiazines and related drugs for inhibition of cell growth and reversal of multidrug resistance. Mol Pharmacol 35: $105-115$

Fromm MF (2000) P-glycoprotein: a defense mechanism limiting oral bioavailability and CNS accumulation of drugs. Int J Clin Pharmacol Ther 38: 69-74.

Ganapathi R, Grabowski D, Rouse W, Riegler F (1984) Differential effect of the calmodulin inhibitor trifluoperazine on cellular accumulation, retention, and cytotoxicity of anthracyclines in doxorubicin (adriamycin)-resistant P388 mouse leukemia cells. Cancer Res 44: 5056-5061.

Gerrard G, Payne E, Baker RJ, Jones DT, Potter M, Prentice HG, Ethell M, McCullough H, Burgess M, Mehta AB, Ganeshaguru K (2004) Clinical effects and P-glycoprotein inhibition in patients with acute myeloid leukemia treated with zosuquidar trihydrochloride, daunorubicin and cytarabine. Haematologica 89: 782-790.

Gottesman MM, Pastan I (1993) Biochemistry of multidrug resistance mediated by the multidrug transporter. Annu Rev Biochem 62: 385-427.

Gottesman MM, Pastan I, Ambudkar SV (1996) P-glycoprotein and multidrug resistance. Curr Opin Genet Devel 6: 610-617.

Gutmann DA, Ward A, Urbatsch IL, Chang G, van Veen HW (2010) Understanding polyspecificity of multidrug ABC transporters: closing in on the gaps in ABCB1. Trends Biochem Sci 35: 36-42.

Gyemant N, Tanaka M, Antus S, Hohmann J, Csuka O, Mandoky L, Molnar J (2005) In vitro search for synergy between flavonoids and epirubicin on multidrug-resistant cancer cells. In Vivo 19: 367-374.

Harborne JB, Williams CA (2000) Advances in flavonoid research since 1992. Phytochemistry 55: 481-504.

Hendrich AB, Wesolowska O, Michalak K (2001) Trifluoperazine induces domain formation in zwitterionic phosphatidylcholine but not in charged phosphatidylglycerol bilayers. Biochim Biophys Acta 1510: $414-425$.

Hendrich AB, Michalak, K. (2003) Lipids as a target for drugs modulating multidrug resistance of cancer cells. Curr Drug Targ 4: 23-30.

Hendrich AB, Wesolowska O, Motohashi N, Molnar J, Michalak K (2003a) New phenothiazine-type multidrug resistance modifiers: anti-MDR activity versus membrane perturbing potency. Biochem Biophys Res Commun 304: 260-265.

Hendrich AB, Wesolowska O, Pola A, Motohashi N, Molnar J, Michalak K (2003b) Neither lipophilicity nor membrane-perturbing potency of phenothiazine maleates correlate with the ability to inhibit P-glycoprotein transport activity. Mol Membr Biol 20: 53-60.

Higgins CF (2007) Multiple molecular mechanisms for multidrug resistance transporters. Nature 446: 749-757.

Hipfner DR, Deeley RG, Cole SPC (1999) Structural, mechanistic and clinical aspects of MRP1. Biochim Biophys Acta 1461: 359-376.

Hooijberg JH, Broxterman HJ, Scheffer GL, Vrasdonk C, Heijn M, de Jong MC, Scheper RJ, Lankelma J, Pinedo HM (1999) Potent interaction of flavopiridol with MRP1. Br J Cancer 81: 269-276.

Jodoin J, Demeule M, Beliveau R (2002) Inhibition of the multidrug resistance P-glycoprotein activity by green tea polyphenols. Biochim Biopbys Acta 1542: 149-159.

Johnson JD, Wittenauer LA (1983) A fluorescent calmodulin that reports the binding of hydrophobic inhibitory ligands. Biochem $J$ 211: 473-479.

Juliano RL, Ling V (1976) A surface glycoprotein modulating drug permeability in Chinese hamster ovary cell mutants. Biochim Biophys Acta 455: 152-162.

Kane SE (1996) Multidrug resistance of cancer cells. Adv Drug Res 28: $181-252$.

Katayama K, Masuyama K, Yoshioka S, Hasegawa H, Mitsuhashi J, Sugimoto Y (2007) Flavonoids inhibit breast cancer resistance protein-mediated drug resistance: transporter specificity and structureactivity relationship. Cancer Chemother Pharmacol 60: 789-797.

Kaye SB (1988) The multidrug resistance phenotype. Br J Cancer 58: 691-694.

Keppler D, Leier I, Jedlitschky G (1997) Transport of glutathione conjugates and glucuronides by the multidrug resistance proteins MRP1 and MRP2. Biol Chem 378: 787-791.

Kitagawa S, Nabekura T, Takahashi T, Nakamura Y, Sakamoto H, Tano H, Hirai M, Tsukahara G (2005) Structure-activity relationships of the inhibitory effects of flavonoids on P-glycoprotein-mediated transport in KB-C2 cells. Biol Pharm Bull 28: 2274-2278.

Kitagawa S (2006) Inhibitory effects of polyphenols on P-glycoproteinmediated transport. Biol Pharm Bull 29: 1-6. 
Konya A, Andor A, Satorhelyi P, Nemeth K, Kurucz I (2006) Inhibition of the MDR1 transporter by new phenothiazine derivatives. Biochem Biophys Res Commun 346: 45-50.

Kothandan G, Gadhe CG, Madhavan T, Choi CH, Cho SJ (2011) Docking and 3D-QSAR (quantitative structure activity relationship) studies of flavones, the potent inhibitors of P-glycoprotein targeting the nucleotide binding domain. Eur J Med Chem 46: 4078-4088.

Kweon SH, Song JH, Kim TS (2010) Resveratrol-mediated reversal of doxorubicin resistance in acute myeloid leukemia cells via downregulation of MRP1 expression. Biochem Biophys Res Commun 395: $104-110$

Lage H (2003) ABC-transporters: implications on drug resistance from microorganisms to human cancers. Int J Antimicrob Agents 22: 188199.

Lage H (2008) An overview of cancer multidrug resistance: a still unsolved problem. Cell Mol Life Sci 65: 3145-3167.

Lania-Pietrzak B, Michalak K, Hendrich AB, Mosiadz D, Grynkiewicz G, Motohashi N, Shirataki Y (2005) Modulation of MRP1 protein transport by plant, and synthetically modified flavonoids. Life Sci 77: 1879-1891.

Lee CH (2010) Reversing agents for ATP-binding cassette drug transporters. Methods Mol Biol 596: 325-340.

Leier I, Jedlitschky G, Buchholz U, Cole SP, Deeley RG, Keppler D (1994) The MRP gene encodes an ATP-dependent export pump for leukotriene $\mathrm{C} 4$ and structurally related conjugates. $J$ Biol Chem 269: 27807-27810.

Leite DF, Echevarria-Lima J, Salgado LT, Capella MA, Calixto JB, Rumjanek VM (2006) In vivo and in vitro modulation of MDR molecules in murine thymocytes. Int Immunopharmacol 6: 204-215.

Leonard GD, Polgar O, Bates SE (2002) ABC transporters and inhibitors: new targets, new agents. Curr Opin Investig Drugs 3: 1652-1659.

Leslie EM, Mao Q, Oleschuk CJ, Deeley RG, Cole SPC (2001) Modulation of multidrug resistance protein 1 (MRP1/ABCC1) transport and ATPase activities by interaction with dietary flavonoids. Mol Pharmacol 59: 1171-1180.

Leslie EM, Deeley RG, Cole SP (2003) Bioflavonoid stimulation of glutathione transport by the $190-\mathrm{kDa}$ multidrug resistance protein 1 (MRP1). Drug Metab Dispos 31: 11-15.

Leslie EM, Deeley RG, Cole SP (2005) Multidrug resistance proteins: role of P-glycoprotein, MRP1, MRP2, and BCRP (ABCG2) in tissue defense. Toxicol Appl Pharmacol 204: 216-237.

Liu R, Sharom FJ (1996) Site-directed fluorescence labeling of P-glycoprotein on cysteine residues in the nucleotide binding domains. Biochemistry 35: 11865-11873.

Liu R, Siemiarczuk A, Sharom FJ (2000) Intrinsic fluorescence of the P-glycoprotein multidrug transporter: sensitivity of tryptophan residues to binding of drugs and nucleotides. Biochemistry 38: 1492714938.

Loe DW, Almquist KC, Deeley RG, Cole SP (1996) Multidrug resistance protein (MRP)-mediated transport of leukotriene $\mathrm{C} 4$ and chemotherapeutic agents in membrane vesicles. Demonstration of glutathione-dependent vincristine transport. J Biol Chem 271: 96759682.

Loe DW, Deeley RG, Cole SP (1998) Characterization of vincristine transport by the $\mathrm{M}(\mathrm{r}) 190,000$ multidrug resistance protein (MRP): evidence for cotransport with reduced glutathione. Cancer Res 58: 5130-5136.

Loe DW, Deeley RG, Cole SP (2000a) Verapamil stimulates glutathione transport by the $190-\mathrm{kDa}$ multidrug resistance protein 1 (MRP1). J Pharmacol Exp Ther 293: 530-538.

Loe DW, Oleschuk CJ, Deeley RG, Cole SP (2000b) Structure-activity studies of verapamil analogs that modulate transport of leukotriene $\mathrm{C}_{4}$ and reduced glutathione by multidrug resistance protein MRP1. Biochem Biophys Res Commun 275: 795-803.

Loo TW, Bartlett MC, Clarke DM (2003) Simultaneous binding of two different drugs in the binding pocket of the human multidrug resistance P-glycoprotein. J Biol Chem 278: 39706-39710.

Lugo MR, Sharom FJ (2005) Interaction of LDS-751 with P-glycoprotein and mapping of the location of the $\mathrm{R}$ drug binding site. Biochemistry 44: 643-655.

Mao Q, Leslie EM, Deeley RG, Cole SP (1999) ATPase activity of purified and reconstituted multidrug resistance protein MRP1 from drug-selected H69AR cells. Biochim Biophys Acta 1461: 69-82.

Marbeuf-Gueye C, Ettori D, Priebe W, Kozlowski H, Garnier-Suillerot A (1999) Correlation between the kinetics of anthracycline uptake and the resistance factor in cancer cells expressing the multidrug resistance protein or the P-glycoprotein. Biochim Biophys Acta 1450: 374-384.

Marques LO, Lima MS, Soares BG (2004) Trifluoperazine for schizophrenia. Cochrane Database Syst Rev CD003545.

Martin C, Berridge G, Higgins CF, Mistry P, Charlton P, Callaghan R (2000) Communication between multiple drug binding sites on Pglycoprotein. Mol Pharmacol 58: 624-632.

Mavel S, Dikic B, Palakas S, Emond P, Greguric I, de Gracia AG, Mattner F, Garrigos M, Guilloteau D, Katsifis A (2006) Synthesis and biological evaluation of a series of flavone derivatives as po- tential radioligands for imaging the multidrug resistance-associated protein 1 (ABCC1/MRP1). Bioorg Med Chem 14: 1599-1607.

McDevitt CA, Callaghan R (2007) How can we best use structural information on P-glycoprotein to design inhibitors? Pharmacol Ther 113: 429-441.

Michalak K, Wesolowska O, Motohashi N, Molnar J, Hendrich AB (2006) Interactions of phenothiazines with lipid bilayer and their role in multidrug resistance reversal. Curr Drug Targets 7: 1095-1105.

Michalak K, Wesolowska O, Motohashi N, Hendrich AB (2007) The role of the membrane actions of phenothiazines and flavonoids as functional modulators. Top Heterocycl Chem 8: 223 -302.

Molnar J, Molnar A, Mucsi I, Pinter O, Nagy B, Varga A, Motohashi N (2003) Reversal of multidrug resistance in mouse lymphoma cells by phenothiazines. In Vivo 17: 145-149.

Molnar J, Engi H, Hohmann J, Molnar P, Deli J, Wesolowska O, Michalak K, Wang Q (2010) Reversal of multidrug resistance by natural substances from plants. Curr Top Med Chem 10: 1757-1768.

Morris ME, Zhang S (2006) Flavonoid-drug interactions: Effects of flavonoids on ABC transporters. Life Sci 78: 2116-2130.

Morschhauser F, Zinzani PL, Burgess M, Sloots L, Bouafia F, Dumontet C (2007) Phase I/II trial of a P-glycoprotein inhibitor, Zosuquidar.3 HCl trihydrochloride (LY335979), given orally in combination with the CHOP regimen in patients with non-Hodgkin's lymphoma. Leuk Lymphoma 48: 708-715.

Motohashi N, Kurihara T, Kawase M, Hever A, Tanaka M, Szabo D, Nacsa J, Yamanaka W, Kerim A, Molnar J (1997) Drug resistance reversal, anti-mutagenicity and antiretroviral effect of phthalimidoand chloroethyl-phenothiazines. Anticancer Res 17: 3537-3543.

$\mathrm{Na}$ HK, Surh YJ (2006) Intracellular signaling network as a prime chemopreventive target of (-)-epigallocatechin gallate. Mol Nutr Food Res 50: $152-159$.

Nabekura T, Kamiyama S, Kitagawa S (2005) Effects of dietary chemopreventive phytochemicals on P-glycoprotein function. Biochem Biophys Res Commun 327: 866-870.

Nabekura T, Yamaki T, Kitagawa S (2008) Effects of chemopreventive citrus phytochemicals on human P-glycoprotein and multidrug resistance protein 1. Eur J Pharmacol 600: 45-49.

Nguyen H, Zhang S, Morris ME (2003) Effect of flavonoids on MRP1-mediated transport in Panc-1 cells. J Pharm Sci 92: 250-257.

Ohtani H, Ikegawa T, Honda Y, Kohyama N, Morimoto S, Shoyama Y, Juichi M, Naito M, Tsuruo T, Sawada Y (2007) Effects of various methoxyflavones on vincristine uptake and multidrug resistance to vincristine in P-gP-overexpressing K562/ADM cells. Pharm Res 24: 1936-1943.

Okura T, Ibe M, Umegaki K, Shinozuka K, Yamada S (2010) Effects of dietary ingredients on function and expression of P-glycoprotein in human intestinal epithelial cells. Biol Pharm Bull 33: 255-259.

Pajeva IK, Wiese M, Cordes HP, Seydel JK (1996) Membrane interactions of some catamphiphilic drugs and relation to their multidrugresistance-reversing ability. J Cancer Res Clin Oncol 122: 27-40.

Pajeva IK, Wiese M (1998) Molecular modeling of phenothiazines and related drugs as multidrug resistance modifiers: a comparative molecular field analysis study. J Med Chem 41: 1815-1826.

Pajeva IK, Globisch C, Wiese M (2009) Combined pharmacophore modeling, docking, and 3D QSAR studies of ABCB1 and ABCC1 transporter inhibitors. ChemMedChem 4: 1883-1896.

Patanasethanont D, Nagai J, Matsuura C, Fukui K, Sutthanut K, Sripanidkulchai BO, Yumoto R, Takano M (2007a) Modulation of function of multidrug resistance associated-proteins by Kaempferia parviflora extracts and their components. Eur J Pharmacol 566: 67-74.

Patanasethanont D, Nagai J, Yumoto R, Murakami T, Sutthanut K, Sripanidkulchai BO, Yenjai C, Takano M (2007b) Effects of Kaempferia parviflora extracts and their flavone constituents on P-glycoprotein function. J Pharm Sci 96: 223-233.

Payen LF, Gao M, Westlake CJ, Cole SP, Deeley RG (2003) Role of carboxylate residues adjacent to the conserved core Walker B motifs in the catalytic cycle of multidrug resistance protein 1 (ABCC1). $J$ Biol Chem 278: 38537-38547.

Peroutka SJ, Synder SH (1980) Relationship of neuroleptic drug effects at brain dopamine, serotonin, alpha-adrenergic, and histamine receptors to clinical potency. Am J Psychiatry 137: 1518-1522.

Phang JM, Poore CM, Lopaczynska J, Yeh GC (1993) Flavonol-stimulated efflux of 7,12-dimethylbenz(a)anthracene in multidrug-resistant breast cancer cells. Cancer Res 53: 5977-5981.

Pirola L, Frojdo S (2008) Resveratrol: one molecule, many targets. IUBMB Life 60: 323-332.

Potter GA, Patterson LH, Wanogho E, Perry PJ, Butler PC, Ijaz T, Ruparelia KC, Lamb JH, Farmer PB, Stanley LA, Burke MD (2002) The cancer preventative agent resveratrol is converted to the anticancer agent piceatannol by the cytochrome P450 enzyme CYP1B1. Br J Cancer 86: 774-778.

Pulaski L, Jedlitschky G, Leier I, Buchholz U, Keppler D (1996) Identification of the multidrug-resistance protein (MRP) as the glutathione-S-conjugate export pump of erythrocytes. Eur J Biochem 241: 644-648. 
Quan F, Pan C, Ma Q, Zhang S, Yan L (2008) Reversal effect of resveratrol on multidrug resistance in KBv200 cell line. Biomed Pharmacother 62: 622-629.

Raderer M, Scheithauer W (1993) Clinical trials of agents that reverse multidrug resistance. A literature review. Cancer 72: 3553-3563.

Ramu A, Ramu N (1992) Reversal of multidrug resistance by phenothiazines and structurally related compounds. Cancer Chemother Pharmacol 30: 165-173.

Raviv Y, Pollard HB, Bruggemann EP, Pastan I, Gottesman MM (1990) Photosensitized labeling of a functional multidrug transporter in living drug-resistant tumor cells. J Biol Chem 265: 3975-3980.

Rosenberg MF, Oleschuk CJ, Wu P, Mao Q, Deeley RG, Cole SP, Ford RC (2010) Structure of a human multidrug transporter in an inward-facing conformation. I Struct Biol 170: 540-547.

Roupe KA, Remsberg CM, Yanez JA, Davies NM (2006) Pharmacometrics of stilbenes: seguing towards the clinic. Curr Clin Pharmacol 1: $81-101$.

Rychlik B, Balcerczyk A, Klimczak A, Bartosz G (2003) The role of multidrug resistance protein 1 (MRP1) in transport of fluorescent anions across the human erythrocyte membrane. J Membr Biol 193: 79-90.

Safa AR, Agresti M, Bryk D, Tamai I (1994) N-(p-azido-3-[125I]iodophenethyl)spiperone binds to specific regions of P-glycoprotein and another multidrug binding protein, spiperophilin, in human neuroblastoma cells. Biochemistry 33: 256-265.

Safa AR (1998) Photoaffinity labels for characterizing drug interaction sites of P-glycoprotein. Methods Enzymol 292: 289-307.

Sauna ZE, Ambudkar SV (2000) Evidence for a requirement for ATP hydrolysis at two distinct steps during a single turnover of the catalytic cycle of human P-glycoprotein. Proc Natl Sci USA 97: 25152520 .

Scalbert A, Williamson G (2000) Dietary intake and bioavailability of polyphenols. J Nutr 130: 2073S-2285S.

Schinkel AH (1997) The physiological function of drug-transporting Pglycoproteins. Semin Cancer Biol 8: 161-170.

Schmidt M, Teitge M, Castillo ME, Brandt T, Dobner B, Langner A (2008) Synthesis and biochemical characterization of new phenothiazines and related drugs as MDR reversal agents. Arch Pharm 341: 624-638.

Seelig A (1998) A general pattern for substrate recognition by P-glycoprotein. Eur J Biochem 251: 252-261.

Seelig A, Blatter XL, Wohnsland F (2000) Substrate recognition by Pglycoprotein and the multidrug resistance-associated protein MRP1: a comparison. Int J Clin Pharmacol Ther 38: 111-121.

Senior AE, Al-Shawi MK, Urbatsch IL (1995) The catalytic cycle of P-glycoprotein. FEBS Lett 377: 285-289.

Shapiro AB, Ling V (1997) Positively cooperative sites for drug transport by P-glycoprotein with distinct drug specificities. Eur J Biochem 250: $130-137$.

Shapiro AB, Fox K, Lam P, Ling V (1999) Stimulation of P-glycoprotein-mediated drug transport by prazosin and progesterone. Evidence for a third drug-binding site. Eur J Biochem 259: 841-850.

Sharom FJ (2008) ABC multidrug transporters: structure, function and role in chemoresistance. Pharmacogenomics 9: 105-127.

Shepard RL, Winter MA, Hsaio SC, Pearce HL, Beck WT, Dantzig AH (1998) Effect of modulators on the ATPase activity and vanadate nucleotide trapping of human P-glycoprotein. Biochem Pharmacol 56: 719-727.

Sheu MT, Liou YB, Kao YH, Lin YK, Ho HO (2010) A quantitative structure-activity relationship for the modulation effects of flavonoids on P-glycoprotein-mediated transport. Chem Pharm Bull 58: 1187-1194.

Signorelli P, Ghidoni R (2005) Resveratrol as an anticancer nutrient: molecular basis, open questions and promises. I Nutr Biochem 16: 449-466.

Skovsgaard T, Nielsen D, Maare C, Wassermann K (1994) Cellular resistance to cancer chemotherapy. Int Rev Cytol 156: 77-157.

Stouch TR, Gudmundsson O (2002) Progress in understanding the structure-activity relationships of P-glycoprotein. Adv Drug Deliv Rev 54: 315-328.

Syed SK, Christopherson RI, Roufogalis BD (1998) Reversal of vinblastine transport by chlorpromazine in membrane vesicles from multidrug-resistant human CCRF-CEM leukaemia cells. Br J Cancer 78: $321-327$.

Szabo D, Szabo GJ, Ocsovszki I, Aszalos A, Molnar J (1999) Antipsychotic drugs reverse multidrug resistance of tumor cell lines and human AML cells ex-vivo. Cancer Lett 139: 115-119.

Tawari NR, Bag S, Degani MS (2008) Pharmacophore mapping of a series of pyrrolopyrimidines, indolopyrimidines and their congeners as multidrug-resistance-associated protein (MRP1) modulators. J Mol Model 14: 911-921.

Teodori E, Dei S, Martelli C, Scapecchi S, Gualtieri F (2006) The functions and structure of $\mathrm{ABC}$ transporters: implications for the design of new inhibitors of Pgp and MRP1 to control multidrug resistance (MDR). Curr Drug Targets 7: 893-909.
Tian X, Yang X, Wang K (2006) The efflux of flavonoids morin, isorhamnetin-3-O-rutinoside and diosmetin-7-O-beta-D-xylopyranosyl-(1-6)-beta-D-glucopyranoside in the human intestinal cell line caco-2. Pharm Res 23: 1721-1728.

Trompier D, Baubichon-Cortay H, Chang XB, Maitrejean M, Barron D, Riordon JR, Di Pietro A (2003) Multiple flavonoid-binding sites within multidrug resistance protein MRP1. Cell Mol Life Sci 60: 2164-2177.

Tsakovska IM (2003) QSAR and 3D-QSAR of phenothiazine type multidrug resistance modulators in P388/ADR cells. Bioorg Med Chem 11: 2889-2899.

Tsakovska I, Pajeva I (2006) Phenothiazines and structurally related compounds as modulators of cancer multidrug resistance. Curr Drug Targets 7: 1123-1134.

Tsuruo T, Iida H, Tsukagoshi S, Sakurai Y (1982) Increased accumulation of vincristine and adriamycin in drug-resistant P388 tumor cells following incubation with calcium antagonists and calmodulin inhibitors. Cancer Res 42: 4730-4733.

van Zanden JJ, Geraets L, Wortelboer HM, van Bladeren PJ, Rietjens IM, Cnubben NH (2004) Structural requirements for the flavonoidmediated modulation of glutathione S-transferase P1-1 and GS-X pump activity in MCF7 breast cancer cells. Biochem Pharmacol 67: 1607-1617.

van Zanden JJ, Wortelboer HM, Bijlsma S, Punt A, Usta M, Bladeren PJ, Rietjens IM, Cnubben NH (2005) Quantitative structure activity relationship studies on the flavonoid mediated inhibition of multidrug resistance proteins 1 and 2. Biochem Pharmacol 69: 699-708.

Versantvoort CH, Schuurhuis GJ, Pinedo HM, Eekman CA, Kuiper CM, Lankelma J, Broxterman HJ (1993) Genistein modulates the decreased drug accumulation in non-P-glycoprotein mediated multidrug resistant tumour cells. Br J Cancer 68: 939-946.

Versantvoort CH, Rhodes T, Twentyman PR (1996) Acceleration of MRP-associated efflux of rhodamine 123 by genistein and related compounds. Br J Cancer 74: 1949-1954.

Wang EJ, Barecki-Roach M, Johnson WW (2002) Elevation of P-glycoprotein function by a catechin in green tea. Biochem Biophys Res Commun 297: 412-418.

Wang RB, Kuo CL, Lien LL, Lien EJ (2003) Structure-activity relationship: analyses of P-glycoprotein substrates and inhibitors. J Clin Pharm Ther 28: 203-228.

Wang Y, Cao J, Zeng S (2005) Involvement of P-glycoprotein in regulating cellular levels of Ginkgo flavonols: quercetin, kaempferol, and isorhamnetin. I Pharm Pharmacol 57: 751-758.

Wang JS, Zhu HJ, Markowitz JS, Donovan JL, Devane CL (2006) Evaluation of antipsychotic drugs as inhibitors of multidrug resistance transporter P-glycoprotein. Psychopharmacology 187: 415-423.

Wesolowska O, Molnar J, Motohashi N, Michalak K (2002) Inhibition of P-glycoprotein transport function by N-acylphenothiazines. Anticancer Res 22: 2863-2867.

Wesolowska O, Mosiadz D, Motohashi N, Kawase M, Michalak K (2005a) Phenothiazine maleates stimulate MRP1 transport activity in human erythrocytes. Biochim Biophys Acta 1720: 52-58.

Wesolowska O, Paprocka M, Kozlak J, Motohashi N, Dus D, Michalak $\mathrm{K}$ (2005b) Human sarcoma cell lines MES-SA and MES-SA/Dx5 as a model for multidrug resistance modulators screening. Anticancer Res 25: 383-389.

Wesolowska O, Wisniewski J, Duarte N, Ferreira MJ, Michalak K (2007) Inhibition of MRP1 transport activity by phenolic and terpenic compounds isolated from Euphorbia species. Anticancer Res 27: 4127-4133.

Wesolowska O, Molnar J, Ocsovszki I, Michalak K (2009a) Differential effect of phenothiazines on MRP1 and P-glycoprotein activity. In Vivo 23: 943-947.

Wesolowska O, Hendrich AB, Lania-Pietrzak B, Wisniewski J, Molnar J, Ocsovszki I, Michalak K (2009b) Perturbation of the lipid phase of a membrane is not involved in the modulation of MRP1 transport activity by flavonoids. Cell Mol Biol Lett 14: 199-221.

Wesolowska O, Kuzdzal M, Strancar J, Michalak K (2009c) Interaction of the chemopreventive agent resveratrol and its metabolite, piceatannol, with model membranes. Biochim Biophys Acta 1788: 1851-1860.

Wesolowska O, Wisniewski J, Sroda K, Krawczenko A, Bielawska-Pohl A, Paprocka M, Dus D, Michalak K (2010a) 8-Prenylnaringenin is an inhibitor of multidrug resistance-associated transporters, P-glycoprotein and MRP1. Eur J Pharmacol 644: 32-40.

Wesolowska O, Wisniewski J, Bielawska-Pohl A, Paprocka M, Duarte N, Ferreira MJ, Dus D, Michalak K (2010b) Stilbenes as multidrug resistance modulators and apoptosis inducers in human adenocarcinoma cells. Anticancer Res 30: 4587-4593.

Wesolowska O, Michalak K, Hendrich AB (2011) Direct visualization of phase separation induced by phenothiazine-type antipsychotic drugs in model lipid membranes. Mol Membr Biol. 28: 103-114.

Wong IL, Chan KF, Tsang KH, Lam CY, Zhao Y, Chan TH, Chow LM (2009) Modulation of multidrug resistance protein 1 (MRP1/ ABCC1)-mediated multidrug resistance by bivalent apigenin homodimers and their derivatives. J Med Chem 52: 5311-5322. 
Wu CP, Calcagno AM, Hladky SB, Ambudkar SV, Barrand MA (2005) Modulatory effects of plant phenols on human multidrug-resistance proteins 1, 4 and 5 (ABCC1, 4 and 5). FEBS J 272: 4725-4740.

Yang R, Cui L. Hou Y, Riordan JR, Chang X (2003) ATP binding to the first nucleotide binding domain of multidrug resistance-associated protein plays a regulatory role at low nucleotide concentration, whereas ATP hydrolysis at the second plays a dominant role in ATP-dependent leukotriene C4 transport. I Biol Chem 278: 30764-30771.

Yang R, McBride A, Hou Y, Goldberg A, Chang X (2005) Nucleotide dissociation from NBD1 promotes solute transport by MRP1. Biochim Biophys Acta 1668: 248-261.

Yu R, Jiao JJ, Duh JL, Gudehithlu K, Tan TH, Kong AN (1997) Activation of mitogen-activated protein kinases by green tea polyphe- nols: potential signaling pathways in the regulation of antioxidantresponsive element-mediated phase II enzyme gene expression. Carcinogenesis 18: 451-456.

Zamora JM, Pearce HL, Beck WT (1988) Physical-chemical properties shared by compounds that modulate multidrug resistance in human leukemic cells. Mol Pharmacol 33: 454-462.

Zhang S, Morris ME (2003) Effects of the flavonoids biochanin A, morin, phloretin, and silymarin on P-glycoprotein-mediated transport. J Pharmacol Exp Ther 304: 1258-1267.

Zhang S, Sagawa K, Arnold RD, Tseng E, Wang X, Morris ME (2010) Interactions between the flavonoid biochanin $\mathrm{A}$ and P-glycoprotein substrates in rats: in vitro and in vivo. J Pharm Sci 99: 430-441. 